\title{
Voices of First Responders - Examining Public Safety Communication from the Rural Perspective
}

Findings from User-Centered Interviews Phase 1, Volume 3

\author{
Kristen K. Greene \\ Shaneé Dawkins \\ Mary F. Theofanos \\ Michelle Steves \\ Susanne Furman \\ Yee-Yin Choong \\ Sandra Spickard Prettyman
}

This publication is available free of charge from: https://doi.org/10.6028/NIST.IR.8277

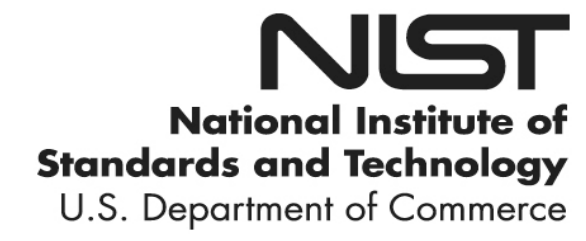


NISTIR 8277

\section{Voices of First Responders - Examining Public Safety Communication from the Rural Perspective} Findings from User-Centered Interviews

Phase 1, Volume 3

Kristen K. Greene

Shaneé Dawkins Michelle Steves

Susanne Furman

Yee-Yin Choong

Information Access Division

Information Technology Laboratory

Mary F. Theofanos

Office of Data and Informatics

Material Measurement Laboratory

Sandra Spickard Prettyman

Culture Catalyst, LLC

This publication is available free of charge from: https://doi.org/10.6028/NIST.IR.8277

November 2019

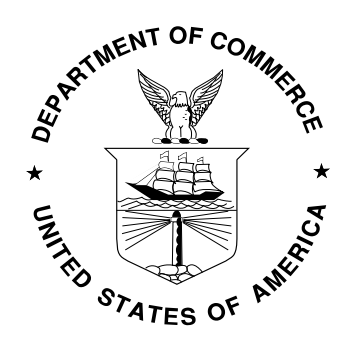

U.S. Department of Commerce Wilbur L. Ross, Jr., Secretary

National Institute of Standards and Technology Walter Copan, NIST Director and Undersecretary of Commerce for Standards and Technology 
Certain commercial entities, equipment, or materials may be identified in this document in order to describe an experimental procedure or concept adequately. Such identification is not intended to imply recommendation or endorsement by the National Institute of Standards and Technology, nor is it intended to imply that the entities, materials, or equipment are necessarily the best available for the purpose.

National Institute of Standards and Technology Interagency or Internal Report 8277 Natl. Inst. Stand. Technol. Interag. Intern. Rep. 8277, 46 pages (November 2019)

This publication is available free of charge from: https://doi.org/10.6028/NIST.IR.8277 


\section{Voices of First Responders Series}

This report is a part of a series of publications amplifying the voices of first responders (VoFR) in four public safety disciplines: Communication Center \& 9-1-1 Services (COMMS); Emergency Medical Services (EMS); Fire Service (FF); and Law Enforcement (LE). The VoFR series reports on the experiences of first responders with communication technology, including their needs for, and problems with, communication technology.

Publications in this series are primarily intended for designers, developers, vendors, and researchers of public safety communication technology, as well as for public safety administrators and decision-makers.

Published as a part of the VoFR series include NIST reports, conference papers, presentations, posters, articles and blog posts, a book chapter, and a web tool for disseminating the research results and data collected from the interviews with and survey of first responders. The reports from which all published materials are derived are listed below and can be accessed from the PSCR User Interface/ User Experience Publications webpage at: https://www.nist.gov/ctl/pscr/user-interface-user-experience-publications. The PSCR Usability Results Tool, providing access to results of the large-scale survey and in-depth interviews with first responders across the U.S. about their communication technology use, can be accessed via https://publicsafety.nist.gov/. The datasets from this research project are available via https://doi.org/10.18434/mds2-2820.

\section{Voices of First Responders}

* How to Facilitate Adoption and Usage of Communication Technology: An Integrated Analysis of Qualitative and Quantitative Findings (NISTIR 8443) https://doi.org/10.6028/NIST.IR.8443

* COMMS (NIST SP 1286pt1)

* EMS (NIST SP 1286pt2) https://doi.org/10.6028/NIST.SP.1286pt2

* FF (NIST SP 1286pt3) https://doi.org/10.6028/NIST.SP.1286pt3

* LE (NIST SP 1286pt4) https://doi.org/10.6028/NIST.SP.1286pt4

Phase 1: Findings from User-Centered Interviews

* Volume 1 - Identifying Public Safety Communication Problems (NISTIR 8216) https://doi.org/10.6028/NIST.IR.8216

* Volume 2 - Examining Public Safety Communication Problems and Requested Functionality (NISTIR 8245) https://doi.org/10.6028/NIST.IR.8245

* Volume 3 - Examining Public Safety Communication from the Rural Perspective (NISTIR 8277) https://doi.org/10.6028/NIST.IR.8277

* Volume 4 - Examining Public Safety Communication from the Perspective of 9-1-1 Call Takers and Dispatchers (NISTIR 8295) https://doi.org/10.6028/NIST.IR.8295

* Volume 5 - Applying Human Factors and Ergonomics Knowledge to Improve the Usability of Public Safety Communications Technology (NISTIR 8340) https://doi.org/10.6028/NIST.IR.8340

Phase 2: Nationwide Survey

* Volume 1 - Methodology: Development, Dissemination, and Demographics (NISTIR 8288) https://doi.org/10.6028/NIST.IR.8288

* Volume 2 - Mobile Devices, Applications, and Futuristic Technology (NISTIR 8314) https://doi.org/10.6028/NIST.IR.8314

* Volume 3 - Day-to-Day Technology (NISTIR 8400) https://doi.org/10.6028/NIST.IR.8400

* Volume 4 - Statistical Analysis Results (NISTIR 8444) https://doi.org/10.6028/NIST.IR.8444 


\begin{abstract}
With the newly created Nationwide Public Safety Broadband Network (NPSBN), the public safety community has a unique opportunity to review and improve communication technology for first responders, in urban, suburban, and rural areas. Understanding the problems and challenges currently experienced by first responders provides the basis for addressing and developing solutions to improve public safety communication. The National Institute of Standards and Technology Public Safety Communications Research (PSCR) usability team conducted in-depth interviews with approximately 200 first responders representing 13 states in eight Federal Emergency Management Agency (FEMA) regions across the United States. From this larger dataset, this Volume 3 report focuses on the contexts and challenges specifically faced by rural first responders. This Volume utilizes 48 interviews with 63 rural first responders. A qualitative analysis of the transcribed interview data revealed unique issues posed by rural geography and topography; incident types specific to the rural environment; and resource challenges faced by rural first responder departments and agencies. Resource challenges include financial, personnel, and infrastructure. While there are many similarities between rural first responders and their urban and suburban counterparts, this Volume focuses on the unique nature of rural emergency response and its implications for technology needs and development. Understanding the specific challenges faced by first responders in rural communities can provide insight into the types of technology that might help them best respond to incidents effectively, efficiently, and safely.
\end{abstract}

\title{
Key words
}

First responders; Communications technology; Public safety communications research; Qualitative research; Usability; User-centered design; User needs and requirements.

\section{Audience}

This report is primarily intended for designers, developers, vendors, and researchers of public safety communication technology.

\section{Disclaimer}

Any mention of commercial products or reference to commercial organizations is for information only; it does not imply recommendation or endorsement by the National Institute of Standards and Technology, nor does it imply that the products mentioned are necessarily the best available for the purpose. 


\section{Executive Summary}

With the newly created Nationwide Public Safety Broadband Network (NPSBN), the public safety community is in the process of supplementing the use of land mobile radios (LMR) with a technology ecosystem that will include a variety of new and improved communication tools, including a range of broadband data sharing platforms. It is imperative to have a clear understanding of first responder needs, requirements and contexts of use-including urban, suburban, and rural environments-in order for successful deployment and adoption of new communication technology. This Volume 3 report is part of a multi-phase project that is designed to provide an in-depth look at the population of first responders, along with their work environments, their tasks, and their communication needs. In the initial research phase, the National Institute of Standards and Technology Public Safety Communications Research (PSCR) usability team conducted in-depth interviews with approximately 200 first responders representing 13 states in eight Federal Emergency Management Agency (FEMA) regions across the United States. From the larger dataset, this Volume 3 report focuses on the contexts and challenges specifically faced by rural first responders. Focusing specifically on rural first responders allows identification of their contexts of work, and how the rural environment influences the problems they face, and the needs they have, related to communication and technology. Understanding the unique challenges faced by first responders in rural communities can provide insight into the types of technology that might help them best respond to incidents effectively, efficiently, and safely.

This Volume 3 report draws on interviews with 63 rural first responders (48 transcripts) coming from all four first responder disciplines: 911 communications, emergency medical services, fire service, and law enforcement. Findings from this subset of the data show that rural users are in many ways similar to their urban and suburban counterparts. However, the contexts in which they work can be very different, which leads to differences in the technology and communication problems and needs they experience. In particular, there are unique communication and technology issues surrounding rural geography and topography. While some of these issues are similar to those experienced in urban environments, such as dropped calls and coverage issues, the reasons for them are different. Size and distance in rural environments also have implications for technology and incident response. Additionally, rural first responder departments and agencies face resource challenges in three specific areas: financial, personnel, and infrastructure. Often, the need for new or emerging communications technology is trumped by the need for basic gear and tools. Related to personnel, hiring, training, and retention are significant issues faced by rural departments. These personnel issues are true across rural agencies, but are amplified in volunteer departments, magnifying issues related to declining volunteerism across the United States. Finally, the infrastructure resources that first responders have access to can vary widely in rural areas. Taken together these findings paint a picture of the nuanced and unique characteristics of the rural first responder environment and the challenges they face related to communications technology. The document closes with a discussion on the implications for technology improvement and development. The infographic on the next page provides a visual summary of the report. 


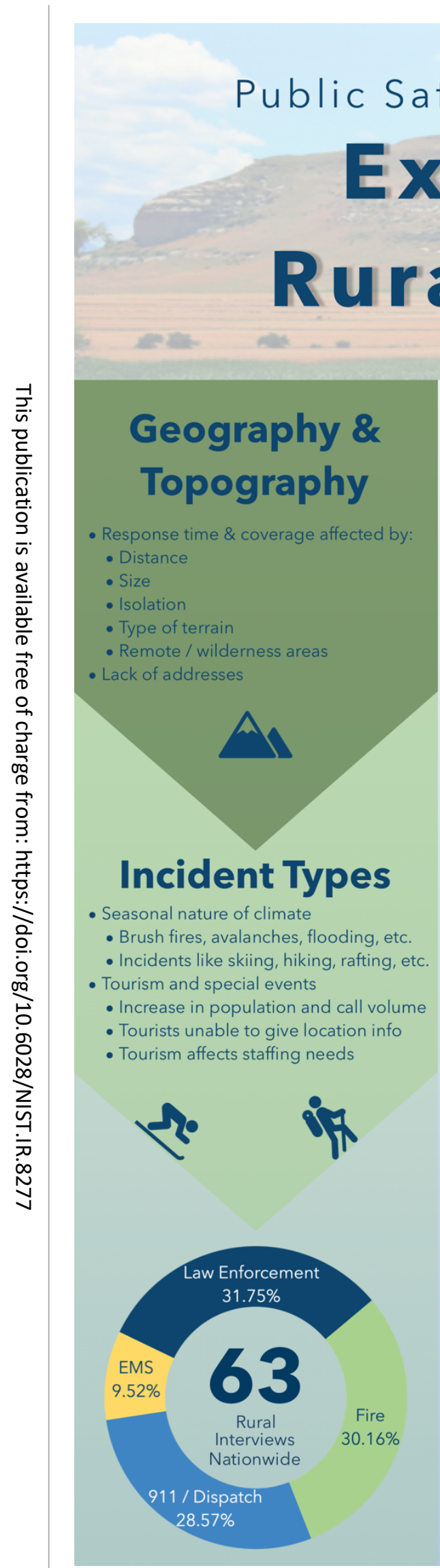

NIST PSCR Usability Team

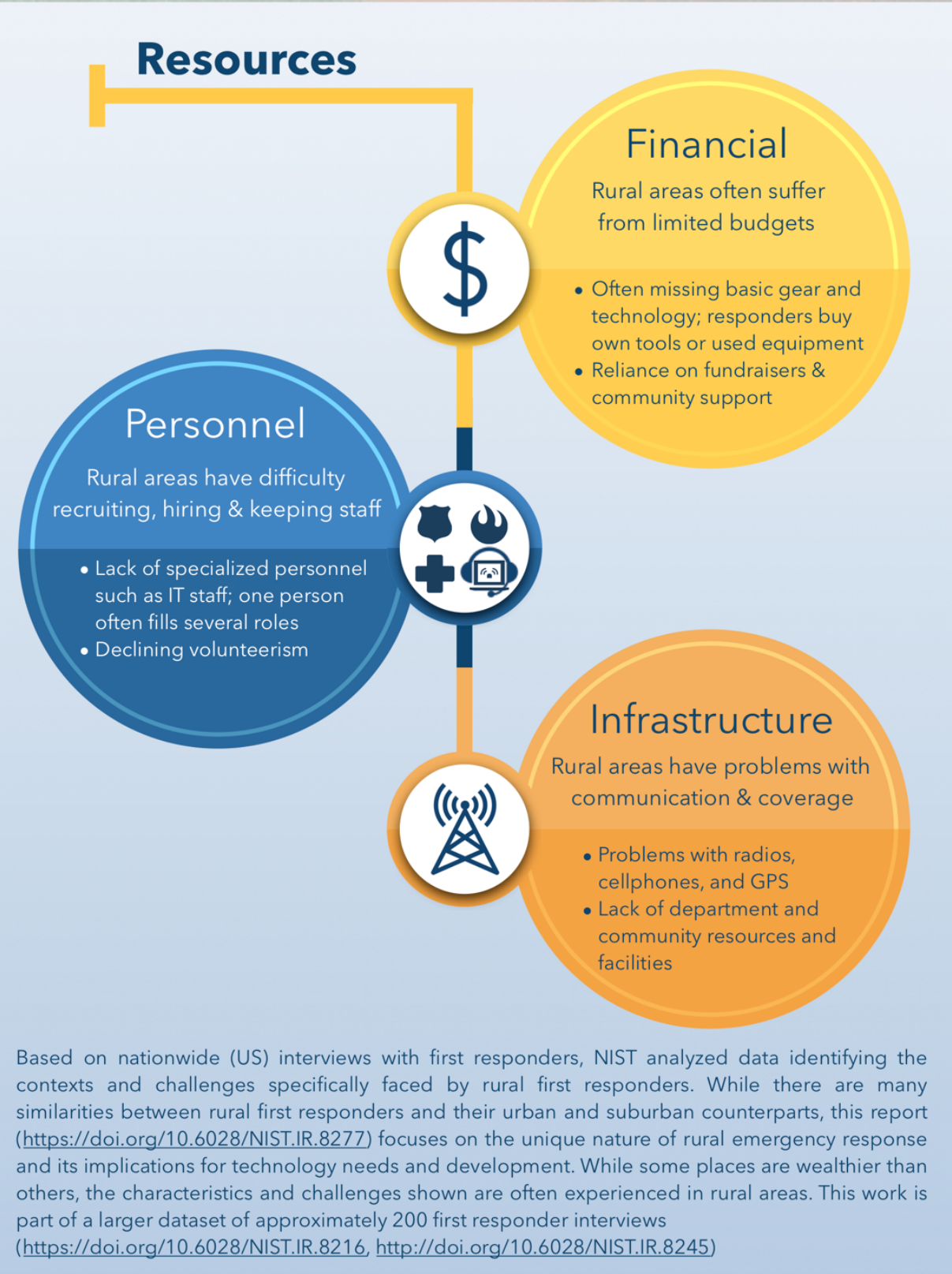

П७) ))

NIST

National Institute of PSCR 


\section{Table of Contents}

ABSTRACT

KEY WORDS

AUDIENCE

DISCLAIMER.

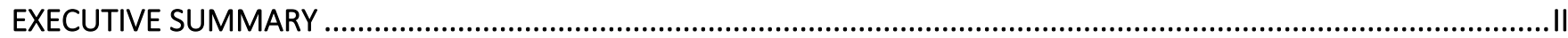

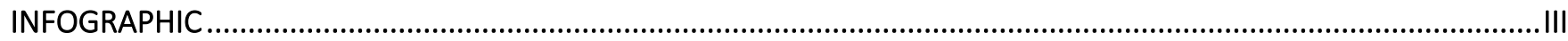

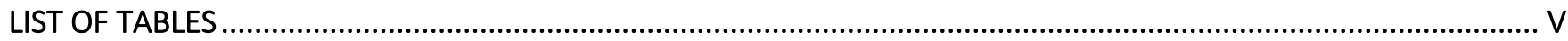

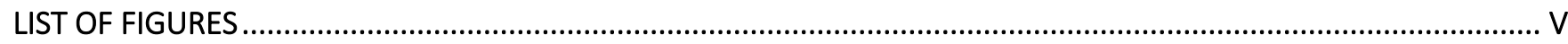

LIST OF ACRONYMS

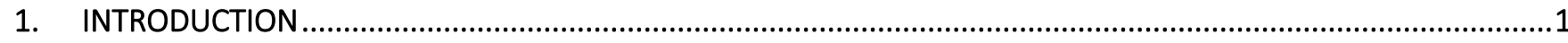

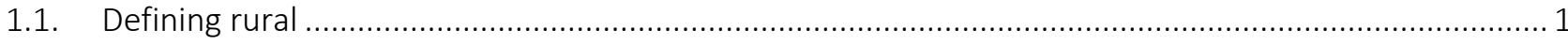

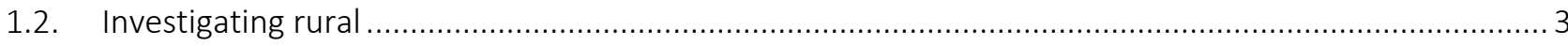

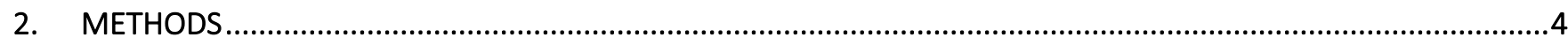

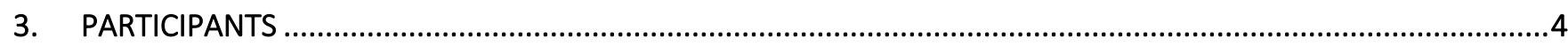

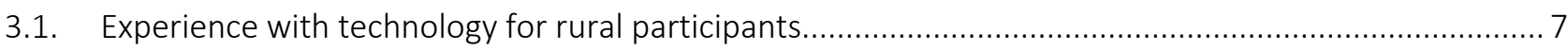

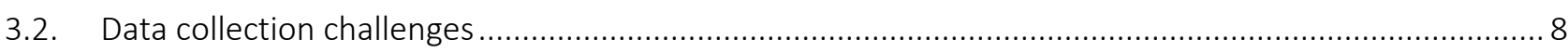

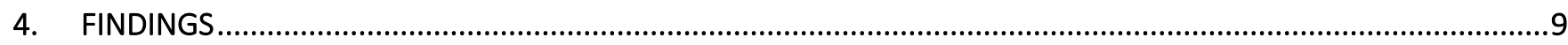

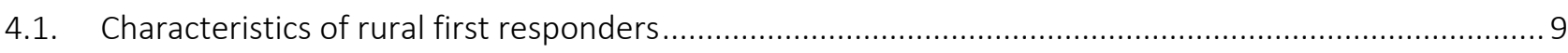

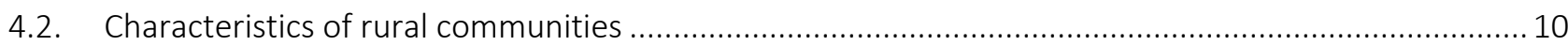

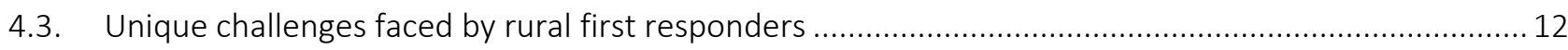

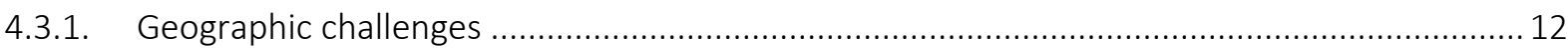

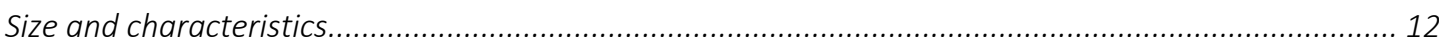

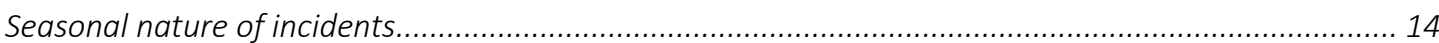

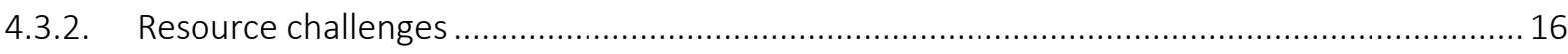

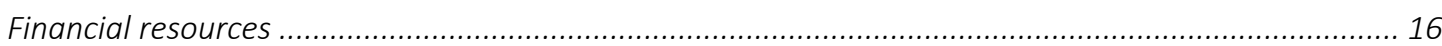

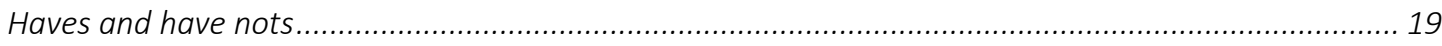

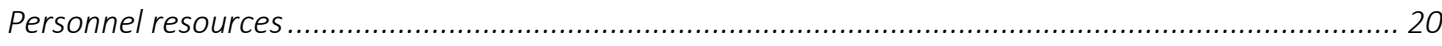

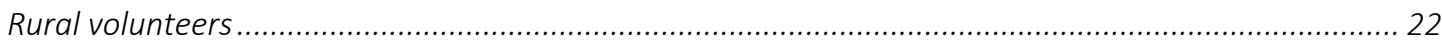

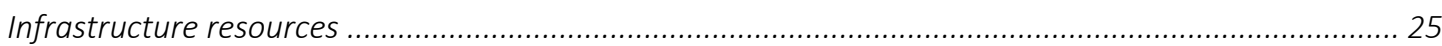

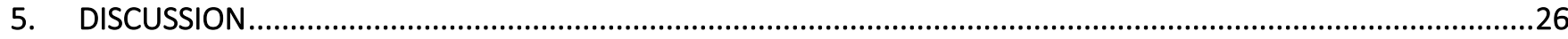

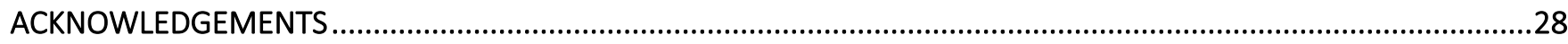

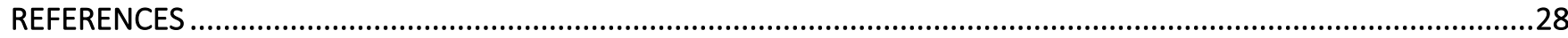

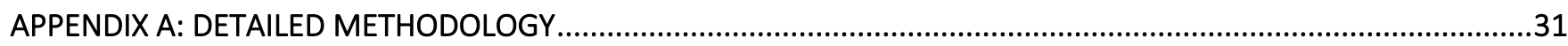

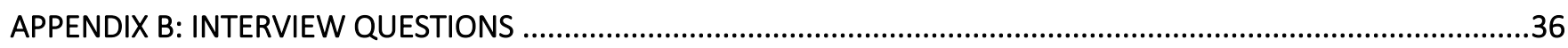

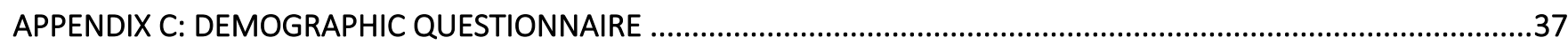




\section{List of Tables}

Table 1. Total number of rural participants interviewed by discipline .............................................................. 5

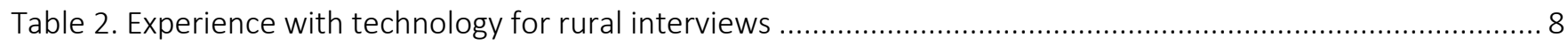

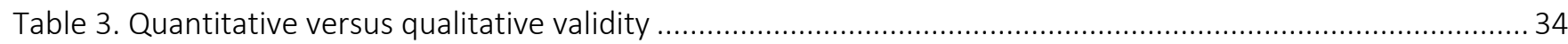

\section{List of Figures}

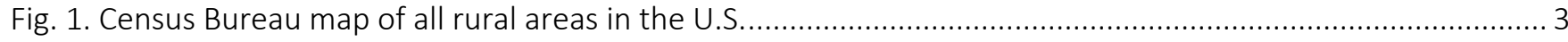

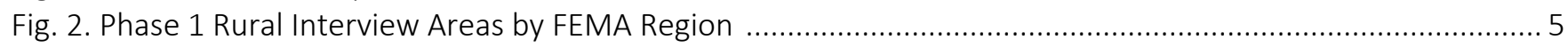

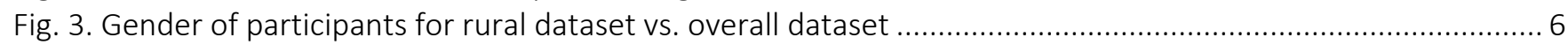

$\underset{\text { J- }}{\text { J. }} \quad$ Fig. 4. Gender of participants by discipline for rural dataset vs. overall dataset vs. national demographics ............ 6

Fig. 5. Participant demographics comparison of the rural dataset vs. overall dataset ......................................... 7 


\section{List of Acronyms}

\section{Census ............... U.S. Census Bureau}

COMMS ............Communications, 911/Dispatch

CPR ..................Cardiopulmonary Resuscitation

EMS ..................Emergency Medical Service

ERS ..................Economic Research Service of the United States Department of Agriculture

FEMA ................Federal Emergency Management Agency

FF......................Fire Service

GPS …...............Global Positioning System

IT .....................Information Technology

LE......................Law Enforcement

LMR ..................Land Mobile Radios

LUCAS ................Lund University Cardiac Assist System

NFPA.................National Fire Protection Association

NPSBN ...............Nationwide Public Safety Broadband Network

PS...................Public Safety

PSCR ................Public Safety Communications Research

US ....................United States 


\section{Introduction}

The public safety community is in the process of supplementing the use of land mobile radios (LMR) with a technology ecosystem that will include a variety of new and improved communication tools, including a range of broadband data sharing platforms. It is imperative to have a clear understanding of first responder needs, requirements and contexts of use in order for successful deployment and adoption of new communication technology [16]. This report is part of a multi-phase project that is designed to provide an in-depth look at the population of first responders, along with their work environments, their tasks, and their communication needs. Phase 1 data collection focused on interviews with approximately 200 first responders (law enforcement, fire fighters, emergency medical services, and 911/dispatch) across the country. The Phase 1 qualitative data informed the design and development of the survey instrument for Phase 2, distributed to first responders nationwide. The Volume 1 report presents findings from the initial phase of qualitative data collection [2]. Volume 2 specifically identifies the technology problems and functionality requested of first responders from the full qualitative dataset [7]. Volumes 1 and 2 represent larger examinations of the entire dataset, while this report, Volume 3, focuses on analyzing a specific subset-the rural interview data. We were interested in exploring the following questions in the current document.

1. What makes the rural environment unique for first responders and their work?

2. What are the specific challenges in rural environments for rural first responders, specifically related to incident response?

3. What are the communication and technology problems and needs of rural first responders?

As noted above, in order to improve current technology and design new technology, it is imperative to understand the users, their tasks, and their specific contexts, including rural users, who are often forgotten. If we are going to design technology to meet their problems and needs, we need to understand rural users and contexts in which they work. In addition, the Nationwide Public Safety Broadband Network (NPSBN) is designed to provide seamless communication for all first responders. As rural communities have unique circumstances compared to urban and suburban communities, this document provides an overview of the type of rural contexts where first responders work, as well as the problems and challenges they face related to communication and technology.

\subsection{Defining rural}

The term "rural" often evokes images of farms and fields, small towns and Main Streets, or rolling hills and open roads. For many people, rural remains an abstract concept, something they can imagine, rather than something they can define. While there is no specific definition of rural that is widely accepted, it seems clear that it is different than what is meant by urban or suburban. As such, the term "rural" serves as a useful concept for analysis. However, trying to delineate what makes a place rural is a difficult task [15]. For example, is it population size or density that defines a place as rural, or is it the administrative boundaries of the area it encompasses?

Often, rural is defined as that which is not urban or suburban. For example, the U.S. Census Bureau (Census) defines rural as any population, housing, or territory that is not included within an urban area (urbanized area or urban cluster). Urban areas include suburban environments as well, as those often surround urban centers [14]. This sometimes creates situations where it is complicated to distinguish exactly what is rural and what is not. For 
example, many rural participants had difficulty deciding whether to choose rural or suburban on the demographic questionnaire (see Sec. 2), noting, as the participant below states, that the area they serve is changing. Several asked if they could choose multiple categories because of this.

We are a very rural community in many instances. The largest part of our area... is rural. But we have some very growing, we're one of the fastest growing [counties] in the state and we have a lot of suburban areas. (COMMS-R-016) ${ }^{1}$

According to the Census, while rural areas are comprised of territory that is not in an urban area, much of the rural population is found in the vicinity of urban areas and not in the more remote locations we often associate with the rural landscape [18].

As another example, the Economic Research Service of the U.S. Department of Agriculture (ERS) notes that the first step in defining rural is identifying urban areas, then all remaining territory is considered rural [4]. This means that rural areas in the U.S. can vary widely in their composition. They can be sparsely populated open land or remote wilderness, a densely populated small town or a housing subdivision on the fringe of an urban area. This highlights the multidimensional nature of the term rural, which is what makes it difficult to define. Rural areas differ in size (square miles), terrain, population and housing density, proximity to large wilderness areas, and climate. While there are differences in what rural areas look like, what they share is the lack of an urban environment.

While there is often a juxtaposition of rural and urban, the ERS notes that what is most important is to consider the purpose of the work or research being done. "The key is to use a rural-urban definition that best fits the needs of a specific activity, recognizing that any simple dichotomy hides a complex rural-urban continuum, with very gentle gradations from one level to the next" [4]. What is important here is that while there are different definitions of rural, the definition utilized should depend upon the purpose for which it is used. Different agencies and different researchers use different definitions because they are interested in rural areas and populations for different reasons - their purpose varies. The ERS notes that defining the line between rural and urban America that best serves the purpose of the project involves answering two questions: 1) Is a given urban area defined in terms of its administrative boundaries, its land-use patterns, or its economic influence; and 2) What is the minimum population size for an area to be considered urban?

This study draws upon the Census definition that identifies rural as territory that is at least five miles or more from an urbanized area, or territory that is at least 2.5 miles from an urban cluster. Thus, rural is comprised of the territory that is not considered to be in an urban area (including suburban areas). Our purpose in this phase of the project was to look at what makes rural unique, especially in the realm of public safety. Given that most first responder agencies and departments are structured around administrative boundaries, we sought out participants who operated within different types of administrative entities (municipalities, counties, etc.) at the rural level (see Sampling Strategy in Appendix A).

\footnotetext{
${ }^{1}$ All direct participant responses are verbatim in blue text and come directly from participant transcripts. See Sec. 4 for details regarding participant responses.
} 


\subsection{Investigating rural}

According to the 2010 census, rural areas cover about $97 \%$ of the land in the U.S., and when looking at a map depicting rural areas in the U.S., it is clear just how much area this represents [Fig. 1]. In addition, approximately $19 \%$ of the U.S. population live in these rural areas-about 60 million people-or 1 in 5 U.S. residents.

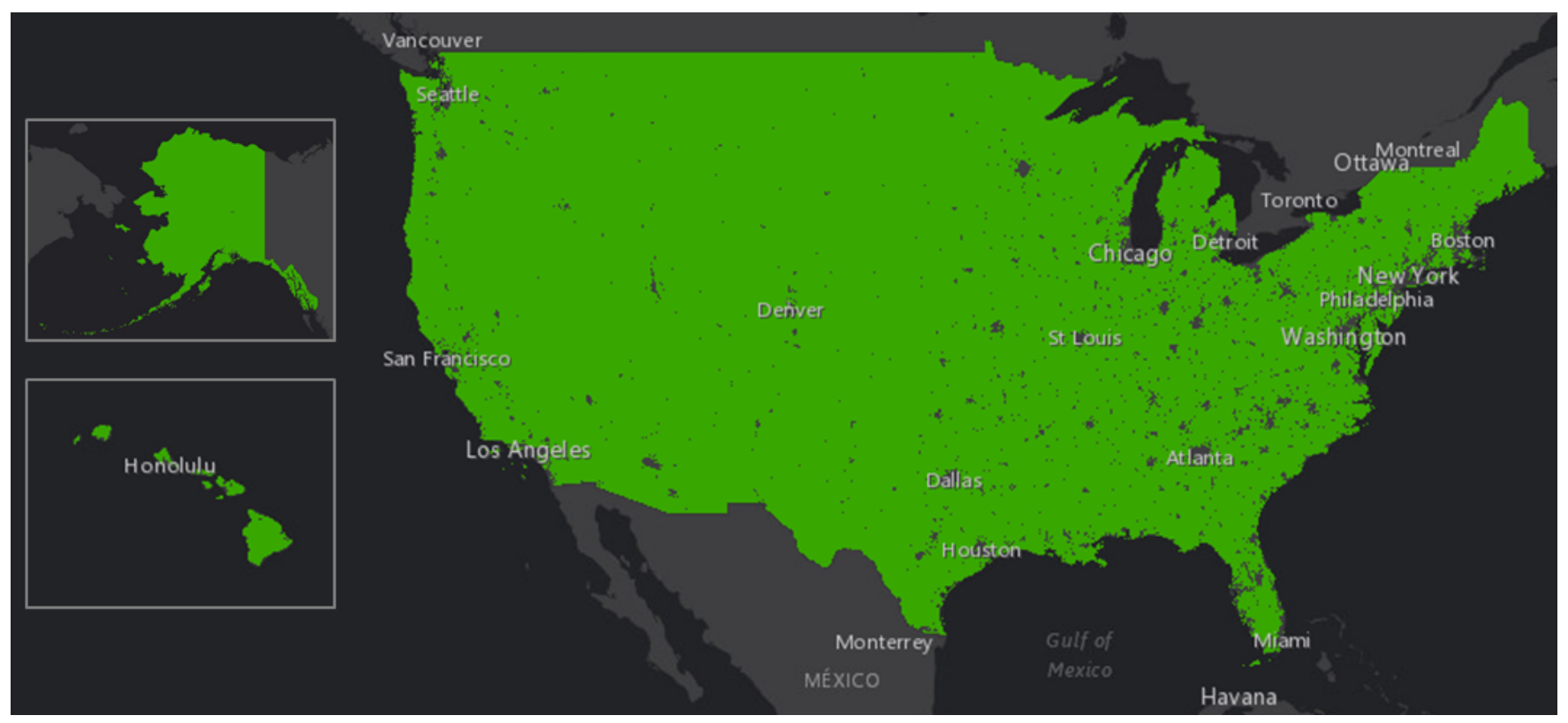

Fig. 1. Census Bureau map of all rural areas in the U.S. [18]

Data from the Census highlight the ways in which rural communities differ from their urban counterparts and why these contextual differences matter. Rural communities are comprised of large land areas that are more sparsely populated, with lower housing density than urban areas. The rural population has a lower median household income and a lower median home value than the urban population. Adults in rural communities have a higher median age (51) than their urban counterparts (45). These are just a few of the demographic differences found in rural areas, but they are differences that may have an impact on the work and experiences of first responders [17].

The context of work matters, in this case the rural context, when trying to understand the experiences of first responders, the problems they face and the needs they have. However, when talking about first responders, the focus is often on urban environments, especially when talking about communication and technology needs. Urban areas are what the media portray most often and what is seen in the news, and many people imagine that this is what being a first responder is like. However, as one of our participants noted:

\section{"Tragedy's not you know just specific to one certain area. Really bad things can happen out here [in rural areas]." (FF-R-049)}

In general, technology development for first responders has not always taken into consideration the rural context and environment. However, rural environments are different than their urban counterparts in ways that affect what first responders do, need, and experience. Understanding the specific challenges faced by first responders in rural communities can provide insight into the types of technology that might help them best respond to incidents effectively, efficiently, and safely, in other words, to have usable technology [11]. Our goal 
in this report is to highlight the unique challenges and needs that rural first responders have related to communication technology so that moving forward their voices and contexts are taken into consideration.

\section{Methods}

As noted above, this report grows out of a multi-phase research project that examines first responder beliefs, perceptions, and experiences related to communication technology. Phase I, the qualitative component, specifically focused on the context of first responder work, especially as it related to communication and first responder use of technology. Phase I includes 158 interviews with 193 first responders across the United States. Data from the Phase I interviews informed Phase II, a largescale quantitative survey designed to investigate first responder problems and needs related to communication technology. This report utilizes a subset of the Phase I data and focuses specifically on the 48 interviews done with 63 first responders who work in rural agencies and departments in order to present the specific issues and experiences they face. The goal here is to examine the rural context in particular and what makes it unique, as well as the specific challenges experienced by rural first responders. Methodological details related to sampling strategy, data collection instruments, and data analysis processes can be found in Appendix A.

\section{Participants}

Due to the varied public safety issues faced in different parts of the country, geographic and cultural diversity were primary considerations for the larger project. Areas for interviews were chosen that provide reasonable coverage of the depth and breadth of geographic and cultural diversity in the U.S. Also taken into consideration was coverage of the varied types of incidents that first responders face. These areas as shown in Fig. 2, align well with the 10 regions defined by the Federal Emergency Management Agency (FEMA). Note that in the map below, we utilize the three-letter code of the major airport in the area in which we collected interviews. For this volume, Volume 3, that is the rural area surrounding the urban area represented by the airport code. 


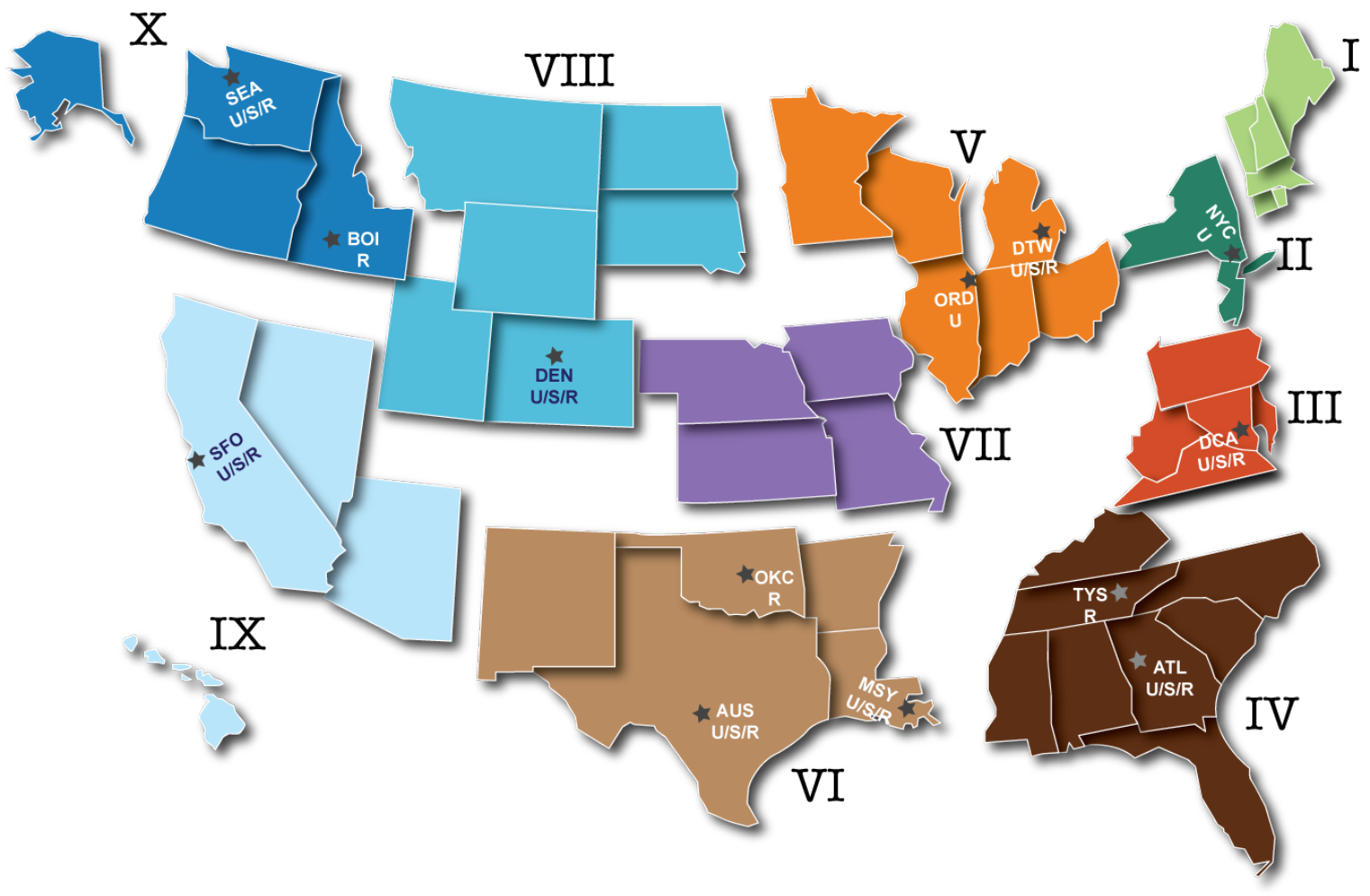

Fig. 2. Phase 1 Rural Interview Areas by FEMA Region ${ }^{2}$ [9]

Of the 193 first responders interviewed for the larger project, 63 (32.64 \%) operated in what we defined as rural areas of the U.S. The 63 rural responders collectively represented all four first responder disciplines [Table 1]. This dataset of 63 rural first responders is the focus of the following analyses.

Table 1. Total number of rural participants interviewed by discipline

\begin{tabular}{llll|c|} 
COMMS & EMS & FF & LE & Total \\
\hline 18 & 6 & 19 & 20 & 63 \\
\hline $28.57 \%$ & $9.52 \%$ & $30.16 \%$ & $31.75 \%$ & \\
\hline
\end{tabular}

At the start of each interview, participants were asked to complete a demographics questionnaire (see Appendix C). The questionnaire captured information about responders' characteristics, experiences, and levels of comfort with technology. Demographic variables for rural first responders largely mirror those of the full dataset [7], with a few interesting exceptions. Characteristics of first responder participants in rural areas are consistent with national numbers [5][6][8][12], showing a male majority (79.37\%), as in the full dataset (86.01\%). However, nearly 50 percent more females were interviewed in the rural data $(20.63 \%)$ than in the overall data (13.99 \%) [Fig. 3]. The larger number of females in the rural dataset may be due to the relative number of

${ }^{2} \mathrm{U}$ - urban locations where interviews were conducted; $\mathrm{S}$ - suburban locations where interviews were conducted; $\mathrm{R}$ - rural locations where interviews were conducted 
COMMS personnel interviewed as compared to the overall dataset [Fig. 4]; nationally, more females are employed as COMMS personnel than their respective FF, EMS, and LE counterparts [5][6][8][12].

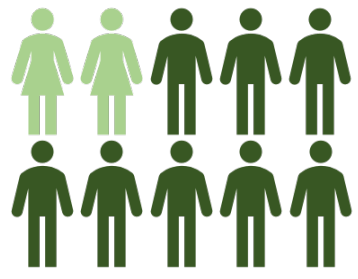

Rural

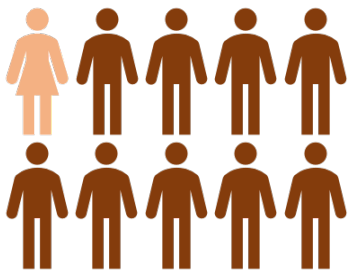

Overall

Fig. 3. Gender of participants for rural dataset vs. overall dataset

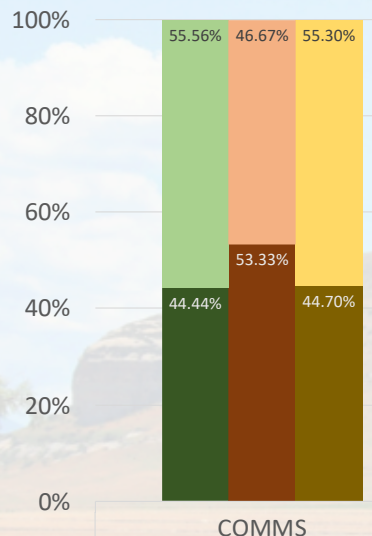

COMMS

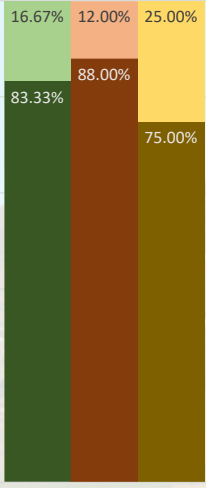

EMS

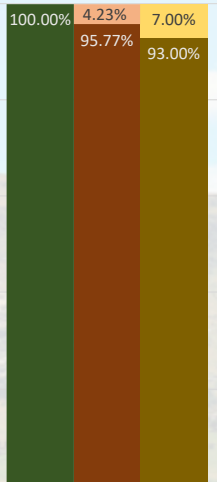

FF

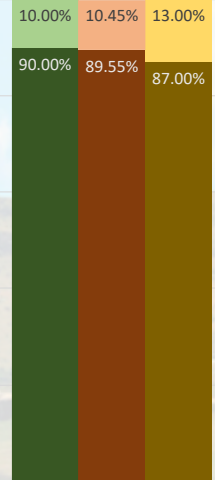

LE
- Rural Females

- Rural Males

Overall Females

- Overall Males

National Females

- National Males

Fig. 4. Gender of participants by discipline for rural dataset vs. overall dataset vs. national demographics Consistent with the overall dataset, more than half of all rural participants fell between the ages of 36 and 55 years (26.98 \% from 36-45; $34.92 \%$ from $46-55$ ) [Fig. 5]. The distribution of total years of service for the rural interview participants also mirrors the larger dataset, with the category of 21-25 years of service being the largest for both ( $20.97 \%$ of rural participants and $18.85 \%$ of the overall dataset) [Fig. 5]. The average for years of service was 16.64 for rural participants versus 17.80 for the overall dataset. 


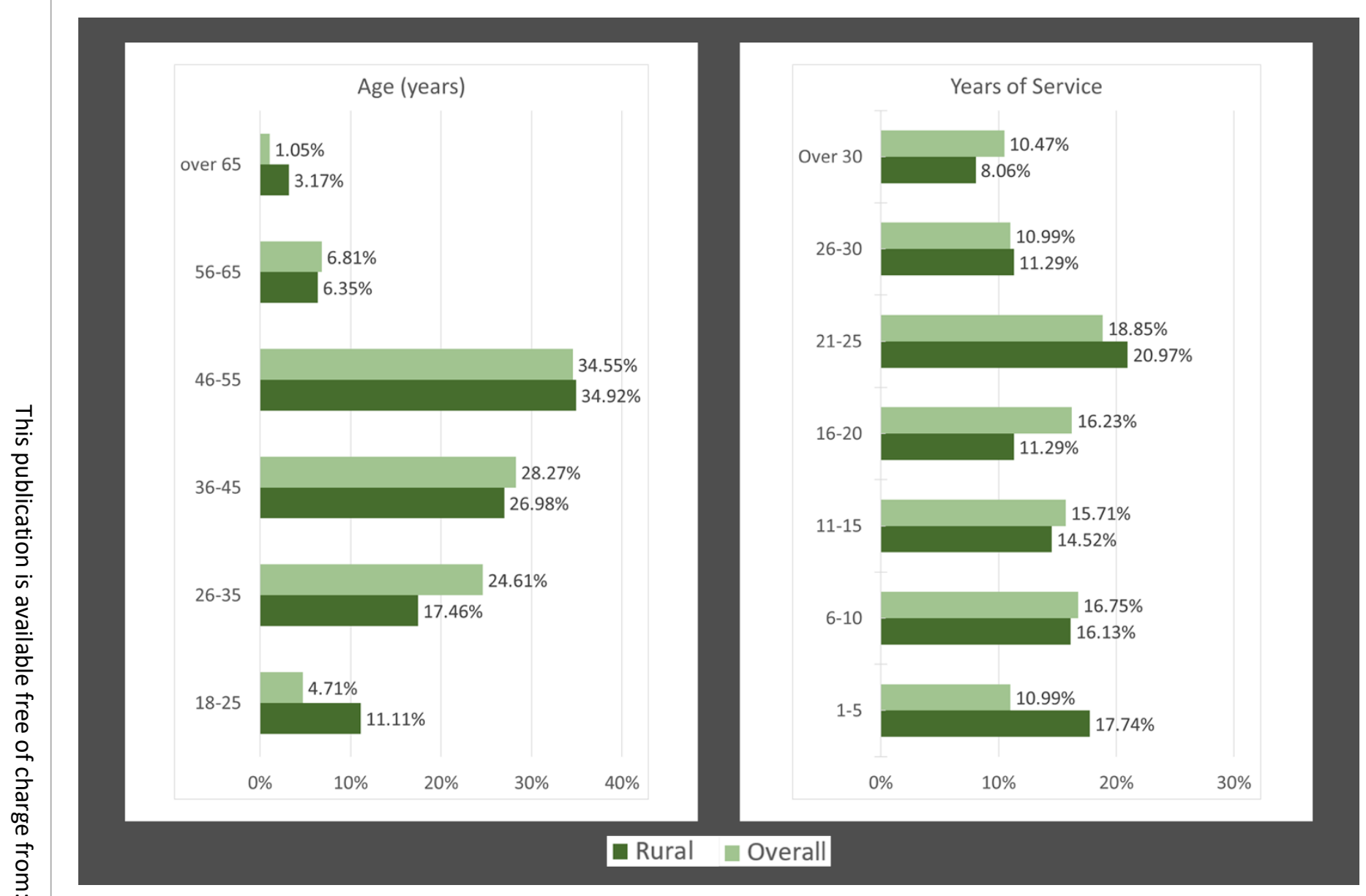

Fig. 5. Participant demographics comparison of the rural dataset vs. overall dataset

Notable differences are in the participants aged 18-25 years and the participants with 1-5 years of service. More than twice the number of participants fell in the lower age range of $18-25$ years $(11.11 \%)$ in the rural data than in the full dataset $(4.71 \%)$. Similarly, the number of rural first responders who have 1-5 years of experience $(17.74 \%)$ is over 50 percent more than in the overall dataset (10.99\%). As will be discussed in the results section, these differences in age and years of service may be because younger responders use rural areas as stepping stones to jobs in larger departments, often creating retention issues in rural areas (see Sec. 4.3.2).

\subsection{Experience with technology for rural participants}

Participants were also asked to self-identify their level of experience with various technologies, as well as their tendencies when adopting new technology [Table 2]. Of rural participants, $65.08 \%$ indicated they could do most things with technology with occasional assistance, and $17.46 \%$ noted they could do everything they wanted/needed without assistance, which is consistent with the percentages in the larger dataset [7]. Approximately $19 \%$ of rural participants indicated they only had limited or some experience using technology, and often needed help. This is higher than in the larger dataset where only $10.99 \%$ of participants self-reported as having some knowledge about and experience with technology and $1.05 \%$ self-reported having limited experience and did not know much about how technology works.

When asked about technology adoption, $39.68 \%$ of rural participants indicated they let others work out the kinks before adopting new technology, which is consistent with the larger dataset (39.27\%). Also consistent 
were the numbers who noted they try the latest technology as soon as it comes out, $17.46 \%$ of the rural participants and $19.90 \%$ of participants in the larger dataset. However, only $28.57 \%$ of rural participants say they follow technology trends, while $38.22 \%$ of the larger dataset chose this option. On the other end of the adoption spectrum, $12.70 \%$ of rural participants adopt new technology when their old technology dies, versus $8.38 \%$ in the larger dataset; and $7.94 \%$ wait until it is required, versus $5.24 \%$ in the larger dataset.

Table 2. Experience with technology for rural interviews

\begin{tabular}{|c|c|c|}
\hline $\begin{array}{l}\text { Q1. Experience with different kinds of technology: (including desktop } \\
\text { or laptop computers, tablets, smartphones, and the internet). }\end{array}$ & $\begin{array}{l}\text { Rural } \\
\text { Percentage }^{a}\end{array}$ & $\begin{array}{l}\text { Overall Dataset } \\
\text { Percentage }^{\mathrm{a}}\end{array}$ \\
\hline $\begin{array}{l}\square \text { I have limited experience using technology and I don't know } \\
\text { much about how technology works. }\end{array}$ & $3.17 \%$ & $1.05 \%$ \\
\hline $\begin{array}{l}\square \quad \text { I have some knowledge about how technology works, but often } \\
\text { need to ask for help to perform more advanced activities - such } \\
\text { as to configure the privacy settings on my cell phone. }\end{array}$ & $15.87 \%$ & $10.99 \%$ \\
\hline $\begin{array}{l}\square \quad \text { I can do most things that I want to do with technology and only } \\
\text { need help occasionally. }\end{array}$ & $65.08 \%$ & $71.20 \%$ \\
\hline $\begin{array}{l}\square \text { I can do all things that I want to do with technology without help } \\
\text { from others. }\end{array}$ & $17.46 \%$ & $18.85 \%$ \\
\hline Q2. In general, when do you adopt new technologies? & $\begin{array}{l}\text { Rural } \\
\text { Percentage }^{a}\end{array}$ & $\begin{array}{l}\text { Overall Dataset } \\
\text { Percentage }^{a}\end{array}$ \\
\hline$\square$ I try the latest technologies as soon as they come out. & $17.46 \%$ & $19.90 \%$ \\
\hline$\square$ I follow technology trends. & $28.57 \%$ & $38.22 \%$ \\
\hline$\square$ I let others work out the kinks first. & $39.68 \%$ & $39.27 \%$ \\
\hline$\square \quad$ I wait until my old technology dies. & $12.70 \%$ & $8.38 \%$ \\
\hline$\square$ I only adopt new technologies when it's required. & $7.94 \%$ & $5.24 \%$ \\
\hline
\end{tabular}

${ }^{a}$ The percentages do not sum to $100 \%$ since participants could select more than one option

Thus, rural participants self-report having slightly less experience with and knowledge about technology, and they adopt technology slightly later than participants in the overall dataset. The protocol did not ask why participants chose the categories they did, so it is impossible to know why the rural numbers vary from the larger dataset, but one hypothesis might be that rural first responders have access to less technology for public safety than their urban and suburban counterparts, and as a result are less comfortable in their use of it and less likely to follow technology trends. This is discussed further in the results section (see Sec. 4.3.2).

\subsection{Data collection challenges}

One of the difficulties experienced during data collection revolved around gaining access to rural first responders. Making an initial contact with rural first responders was hindered by the fact that many did not have department phones, emails, or websites, often utilizing personal cell phones and emails for communication. As noted in Volume 1, in many instances, gaining access to first responders was dependent on referrals from personal and/or professional contacts, or on the use of snowball sampling [2]. This access issue was magnified, as well as challenges with logistics, for the rural demographic. Once contact was made, rural first 
responders were very interested in participating, noting how they often felt left out of research since they were so "small" and as a result felt that their voices did not matter.

In addition to being difficult to initiate contact, it was often difficult to physically access many of these rural areas, especially given some of the terrain and remoteness of the locations. Researchers also had to prepare for a lack of connectivity; GPS did not always function in some of the areas, making navigation difficult and necessitating that offline maps be downloaded in advance. From a time and resource perspective, data collection in these rural departments and agencies costs much more than data collection in metropolitan areas. These data collection challenges may be one reason why rural first responders represent an understudied population, and another reason why it is such an important population to examine here.

\section{Findings}

The following sections present findings from data analysis of the interviews with rural first responders. The best way to present these findings is by using the words of those rural first responders who participated. The participant responses reported in this Volume are exemplars representative of the larger rural dataset. All direct participant responses are verbatim in blue text and come directly from participant transcripts. The convention for referencing these data is the following. Participant responses are followed by a reference in parentheses that is comprised of three parts: discipline (FF; EMS; LE; COMMS); city type (in this case, $\mathrm{R}=$ Rural); and interview number. Thus (FF-R-009) refers to an interview with a fire fighter, from a rural location, who is fire interviewee number 009. This convention provides assurances to the reader of the data's provenance and that the data can quickly and easily be located within the larger dataset when necessary. Note also that moving forward in this document the term urban is used to denote both urban and suburban areas that are found in urban and urban cluster locations.

\subsection{Characteristics of rural first responders}

As noted in Volume 1 [2], it is important to know and understand user characteristics when designing technology. Hackos and Redish [10] note the importance of considering user characteristics beyond their tasks, such as motivation and relationship to work, in their seminal usability textbook. Several related characteristics stood out in the rural dataset when first responders described their work. One was the passion and pride they have for their work, which cuts across all four of the first responder disciplines and is similar to the ways in which first responders in the overall dataset spoke about their work. Their commitment is to helping people and to providing service, and they love their work because it allows them to do this. Many rural participants spoke of "loving" their job, of the "satisfaction" they have in doing it, and of how "rewarding" their work is.

I love my job. It's very rewarding. It's great to help people when they're in need, when they're having the worst day of their life. But it can be stressful because not every day, not every shift ends well and there are times when you just can't help someone as best you want to, you can't. (EMS-R-019)

It's the greatest show on earth... It's fantastic. (LE-R-017)

It's very satisfying to know you can help somebody. (COMMS-R-013)

Rural participants, like their urban counterparts, are dedicated to the profession, enjoy their work and find it rewarding. However, rural first responders also expressed a contradiction about their work-that it could be interesting and exciting but also boring. 
Well I would say that [it] can be boring I think sometimes. I think too that you know it's good work. It's important work. (COMMS-R-009)

Again, it's a rural area. You're kind of out by yourself. We only run three deputies per shift, and they have a pretty good geographic area to cover. It's boredom, you've got to watch the animals, we have a lot of deer wrecks, and just being a rural area, and a lot of times, our deputies are stuck out on maybe a serious call, sometimes 15-20 minutes by themselves, because their nearest backup may be 15 miles across [county redacted ${ }^{3}$ ], so it gets a little boring, but it's pretty interesting. (LE-R-054)

This contradiction was not present in the overall dataset and is something that sets the rural data apart. Urban first responders certainly spoke of their work as interesting and exciting, but never as boring.

In general, rural first responders love their work, in part because they care about the people and the communities they serve. They see their job as helping people and as being part of a public safety community. The quotes below are examples of what we heard across the disciplines from rural first responders.

Pretty much, we're going to go help anybody that needs help, whether it's medical, fire, anything like that. If they need something, just call the fire department, we'll come and help them. I'd say that we're at their disposal for them. So if it was really coming down to, "What do we do?" just be anything for the citizens we work for, pretty much. (FF-R-009) We're one of [counties redacted] that still go and unlock vehicles. So we have the services of unlocking vehicles if we can. If we can assist you, we'll do it. (COMMS-R-010)

We have kids that come in after school... kids can come here and we'll put them on the computer and let them do homework and let them hang out here after school so we try to be really, really inclusive a family environment here. (LE-R-048)

Like their urban counterparts, rural first responders are committed to public service and dedicated to the communities they serve.

\subsection{Characteristics of rural communities}

The context of rural first responder work is linked to the type of communities they serve, and their perceptions of these communities. In addition, the nature of rural communities is often linked to the types of resources present, from geographic to financial. When rural first responders described their communities, they often noted the "rural" nature of the areas and what that meant to them. For some, it meant large, expansive areas that were sparsely populated, while for others it meant small communities that were close-knit and connected.

It's very rural. We don't have a very high crime rate. (COMMS-R-010)

Well like I said it's a lot of farmland. We do have some small towns but they're not real towns really. Some of them have a couple hundred people in them and it's mostly the folks outside of there that we're also serving so the sheriff's department we serve kind of all of these rural areas here out here and those areas that don't have their own police departments especially. (LE-R-046)

${ }^{3}$ Throughout the data, potentially identifying details have been redacted from participant quotes. 
[The call volume is] not very high. Like I say we're small. We don't see as much... as many calls as other agencies do. We actually did some training, where they took us to a larger facility [urban city redacted] and we saw their call volume compared to ours, oh my God [Laughing], oh my God. Yeah, so we maybe get, on a slow day we'll get anywhere from 2 to 3 calls. And on a busy day it could be anywhere from 10 to 15 calls. (COMMS-R-014)

While these descriptions of rural are different, they are connected in that they describe small communities and sparsely populated areas that are connected by large expanses of land (whether farmland, wilderness, or other types of areas).

Many rural first responders also described the family-oriented nature of their agencies and communities, and the ways in which they felt supported by them.

If I had to describe the job, I would say it's a family-oriented department that we work for, a real tight-knit group. (FF-R-009)

The community here, everybody kind of treats everybody as family. I know that there is a lot of, I guess, issues with police officers right now. I haven't ever encountered that in [county redacted]. Like I've walked into a grocery store in uniform, and I get people, 'thank you for your service.' I don't have anybody calling me derogatory names or anything, so definitely it feels like a family in this [area]. (COMMS-R-012)

So it's a good ol' boy city or county you know with everybody knows each other, everybody goes to church with each other. (EMS-R-007)

In many cases, this family orientation means that rural residents often expect first responders to answer a wide variety of calls and to help them with a wide variety of different problems, many of them outside the scope of more fundamental first responder duties surrounding protecting life and property.

I had a lady call who her refrigerator door was stuck, she needed her refrigerator opened. (COMMS-R-014)

That's the uniqueness of our position at the sheriff's office. We do a wide variety of calls where most sheriffs' offices won't even answer those calls... like we still unlock vehicles. Any--we respond to any case or any call that comes into the radio room. If someone, like this morning for instance, a woman was mad because her grandmother posted a picture of her child on her Facebook account. So agencies, this to them would have been like, this is--we're not going out--we're not coming out for that. But here in the sheriff's office we respond to all-because at that moment, that is their emergency. (LE-R-052)

This expectation to help anybody that needs help means being able to juggle many different roles. While call volumes may be low in rural communities, first responders are often expected to respond to all sorts of emergencies and incidents. Their willingness and ability to respond play a large role in the community's perception and support of them.

Additionally, the close-knit nature of many rural communities makes the work very emotionally charged for rural first responders who live and work there. 
... when you're on a scene and it's involving your friends who, people that you know and treat like family it makes it harder and everybody knows everybody you know, kind of a deal in these small towns so we want our stuff to work. (FF-R-048)

While first responders in general care deeply about the people and communities they serve, it is "harder" when you are called to a scene and face an incident involving family and friends.

\subsection{Unique challenges faced by rural first responders}

In many ways, rural first responders are similar to their urban counterparts. They love their work and find it exciting and worthwhile. They all respond to incidents with the goal of protecting life and property, and they all face challenges while trying to do that work. However, the types of incidents they respond to and the challenges they face are often unique to the rural context in which they do their work. Data from this project show these challenges to be concentrated in two major areas: geographic challenges and resource challenges. Differences in geography and topography play key roles in the types of incidents rural first responders face and the ways in which they can and do respond. In addition, while many first responder departments and agencies face resource challenges, these seem to be especially problematic in rural areas. For example, the lack of hospitals in rural environments is a major difference that influences how rural first responders experience and respond to incidents. Below, we focus specifically on those challenges that make the rural environment and experience unique for first responders.

\subsubsection{Geographic challenges}

While rural geography varies across the country, it is also similar in many ways. For example, rural first responder departments and agencies typically cover large distances, which often include remote areas. The particularities of rural geography present unique challenges for rural first responders, from the types of incidents that occur to the types of communication problems they face and the types of technology they need.

\section{Size and characteristics}

The physical size of the community that rural first responders cover and the distances they often need to travel pose specific issues for rural first responders. Size, distance, and isolation have implications for response times, both getting to an incident and transportation to facilities such as hospitals.

It's large and sparsely populated... maybe 15000 to 20000 people in a county that's one of the top 5 largest counties in [state redacted]. So for that you have, you know, mostly farmers or people that are just trying to live off the grid. So you got larger tracks of property, people live farther apart, people are trying to get out of the city. They're trying to avoid the noise, the congestion so they come out here and that's good until you need something like us and you don't realize that, 'Oh, I do live way out of the city and it's great but now I need an ambulance and they're 30 minutes away,' you know. (EMS-R-018)

With large areas to cover, it often takes longer to get to an incident, making response times slower. This can certainly have implications for rural first responders' ability to efficiently accomplish their primary task of protecting people and property in the communities they serve.

Additionally, it is sometimes difficult for rural first responders to find an incident since there may or may not be an actual address associated with a location (third barn on the right of the lane that's just off the dirt road, for example) and GPS does not always provide accurate directions or in some cases any directions. While the data 
from urban areas also highlight the lack of accurate caller location information, this issue seems to be exacerbated in rural areas where distances (and thus response times) are greater. The comment below from a 911 dispatcher is illustrative of what we heard from rural first responders.

There are a lot of instances where we have to look up stuff for our guys because... we are the country and some of the addresses don't-- aren't easy to find. (COMMS-R-014)

Difficulty finding and accessing locations, and sometimes not having addresses at all, means longer response times as rural first responders search for locations. While urban first responders also face issues related to location-based information, the problems are different and will demand different types of solutions [7]. Another issue is the isolation present in many rural areas, for example those that have large expanses of farmland or the remoteness of wilderness areas. Often, this has implications for access to communication, and rural first responders often experience a lack of signal and/or service.

Obviously we're rural, so the radio communication isn't the best. (LE-R-002)

So it's hard to reach certain places, but your southern area is the same thing. So you'll lose service, particularly the further south you go. (COMMS-R-012)

Because it--there are places in [county redacted] where the radios still don't work. If they do work, it's hard to get out on them, or they can't hear. There are places in [county redacted] where cell phones won't work. Or the computers won't work. So you have to have all three of these nowadays. It's hard in our job to limit one and expect it to be 100 $\%$ successful in any operation. (LE-R-052)

There are a lot of places especially in our county that are remote where we just don't get a signal so that's a problem. This is a lot of farmland. This is a lot of places that are kind of remote. (LE-R-046)

Most rural first responders noted how coverage is often a problem, making communication difficult in many areas. Even when they have technology, like radios, cell phones, and computers, they often "don't work." In addition, some rural first responders do not believe that additional technology can actually address the geographic challenges they face. Similar to findings in the full dataset [7], rural first responders prefer to have the communication technology that they currently use work better rather than newer technology that they are not sure will help them given the geographic context of their work.

I think we've got about everything we need out here... it's so remote that I don't know what we could have that would really help... it's not like cameras are really good help... when you think about technology maybe you think about drones-- that's not going to help us out here. What's that going to do for us? I just don't think there's a whole lot of other kind of technology that we need that's going to help us do our job better, really. (LE-R046)

In many cases, technology fails rural first responders, often as a result of the geographical characteristics that are part of their context of work. In addition to the physical size and space of rural areas, the topography is also different, which can also contribute to coverage and communication issues.

And everyone knows that in a lot of wilderness areas, you're not going to have radio communications because you can't put a radio tower in there. And generally, wilderness 
areas are high and mountainous, which means there's valleys and radio signals don't get into valleys. (LE-R-019)

Well whenever they go into certain areas in [county redacted], 'cause we are in the country and it's real country here, a lot of trees and it's a lot of back roads and stuff, they won't be able to hear the information we're giving them and we can't hear the information they're giving us. (COMMS-R-014)

Mountains, water, caves and other topographic challenges contribute to communication issues faced by rural first responders.

The geography and topography also influence the types of incidents rural first responders deal with (farm implements accidents or rock-climbing falls, for example).

Most of our incidents are wild lands/grass fires stuff like that. You know field fires, brush, stuff like that-- hay bales. (FF-R-048)

The big river, when the snow melts, we got a lot of rafting accidents. (LE-R-019)

Some of these types of incidents require specialized training and equipment, which rural first responder agencies and departments may or may not have depending on their financial resources.

So anything like that, two acres, we could put out with our brush truck pretty quick, especially in the morning like that. Our brush truck could put out two acres within, I don't know, 5 or 10 minutes. (FF-R-009)

Being a very active community we do a lot of back country rescue and communications again is one of our biggest issues. So we kind of look at different ways that we can improve communications and have backup communications for those responders that are going out into the field because, especially during winter with avalanches, there's so many additional hazards that the responders face out there. (FF-R-046)

The equipment needed, both for rescue and for communication, varies for rural first responders based on the types of incidents they experience. Whether the context involves deer rutting season or tractor accidents, specific tools and training are often required.

Urban first responders also deal with incidents specific to their environments, but this again highlights how the one-size-fits-all approach may not work for first responder communication technology. What is needed when fighting wildland and grass fires is going to be different than what is needed when dealing with a subway fire. Understanding the contexts in which rural first responders work is imperative in understanding the type of technology they need.

\section{Seasonal nature of incidents}

As noted above, many of the incidents rural first responders deal with are related to the geographic and topographic contexts of rural areas. Many of the incidents also relate to the seasonal nature of the climate in these areas (brush fires, avalanches, and flooding, for example) as well as the tourism that is the focus of some rural areas. As FF-R-046 notes above: "especially during winter with avalanches, there's so many additional hazards that the responders face out there." 
The wildlife-- we get calls on those everyday, or livestock. If it's a sheep, we run sheep from spring to fall. They go back and forth and it just becomes just people calling in you know one lone sheep will get left and people don't like seeing lone sheep out. (COMMSR-008)

So our busiest time is basically middle of December through New Year's. That's when we have the most people. (FF-R-024)

In this case, it is not the geography itself that poses a challenge, but the types of activities that happen during particular times of the year.

The seasonal nature of tourism and special events leads to an increase and decrease in population and call volume.

Summer [call volume] goes up. There's two months in the summer it pretty much doubles which is July and August, and then winter. So our average is about a hundred calls for service a day, and so in the summer it's, you know, 200 calls a day. Some winter-- we will get [high call volume] in the winter at certain holidays. Like president's weekend is a big ski time so everybody, you know, have a bump up in calls then... if there's certain events going on-- so it's very driven, it's driven by tourism. Who is coming and going you know what activities are being promoted. (COMMS-R-010)

And then we also have extra things besides just the daily duties that are actually even bigger in the summer which are special events. So there's rodeos. There's concerts. There's bike events. There's white water stuff with kayaking. There's weddings. There's visiting dignitaries. There's just all stuff that just comes with the summer. And then there's busy weekends like 4th of July weekend or holiday weekends, or there's a big concert in town, so suddenly we have 30000 extra people in town. (EMS-R-007)

Many rural first responders spoke about the difficulty in dealing with the increased call volume they experience during times of year when their populations increase due to an influx of tourists. Adequately staffing and responding to high call volumes becomes a major challenge for these departments and agencies.

Another related issue is that given the high number of tourists, many people who need help do not know the area and are unable to give an accurate location for where they are. This is complicated by the situation described in the previous section where many rural locations do not have specific addresses. In addition, many people are often driving or passing "through" rural areas, they are not necessarily destinations in and of themselves. This means they do not know the terrain and how to operate in it, which can lead to accidents and other incidents requiring assistance by rural first responders.

Well it's, as you know, kind of a tourist community in a rural area, so the calls vary widely depending on the time of the year. In the winter we handle a number of ski calls injuries, motor vehicle accidents just because of slick roads and that sort of thing, some avalanche calls. I guess exposure calls would be other ones and then the typical, you know, vacationers and that can be at any time either summer or winter with the bar fights or the things like that so, during when summer is more outdoor we have a lot of tech rescues that happen in remote areas of the county that often have to have extra different types of apparatus to get to the location and sometimes swift water rescues, so a variety. Many 
people don't know where they are so our interest in technology that helps us to find people is important. (COMMS-R-008)

Urban first responders also face seasonal issues, such as incidents in extreme weather [3], however the issues are different in rural environments, exacerbated by the nature and size of rural geography.

\subsubsection{Resource challenges}

Our data show that rural first responder departments face significant resource challenges and often tend to be very under-resourced, although there are notable exceptions, which will be discussed below. Rural communities face challenges related to financial resources, personnel resources, and infrastructure resources, all of which influence the ability of rural first responders to accomplish their primary tasks efficiently, effectively, and safely.

\section{Financial resources}

Rural first responders in this study described how their departments suffered from a lack of funding, and the implications of this for their work. Across disciplines, rural first responders noted how their funding often came from fundraisers or was highly dependent on support from their communities, and how this funding was woefully inadequate to support their work and the tools they need to accomplish it.

It's all--everything in the public sector is about money. You have a limited supply of it. People think you don't. But we get 6 mils property tax that's all we have. No sales tax. No user fees. No nothing. We get 6 mils property tax and our tax is based--is dependent on the value of the nuclear plant which reduced $4 \%$ every year. So my budget constantly goes down and my expenses go up and my needs go up. So I mean... that's where we're at. (FF-R-051)

You're never going to have enough money to do everything you want to do right now. It's just not the way emergency services works. It's all plea to the public for money, you know. So it's frustrating, but, you know, every day when you go out there you need to keep that in mind. These people are the ones that are paying for you so when you go out there you know you can't say, 'oh you're an idiot you called 911 for this?' You have to, like I say, solve the problem, fix it that's what they're calling you for, so you know that helps you in the long run. They think back on that and say, 'oh man, I think I'm going to vote yes for this cause because it helps the ambulance.' (EMS-R-018)

It is a huge issue. I mean funding is a huge issue. Up until I think we're coming up on the first year of having the sales tax for our county and other than that we were funded by a yearly fundraiser. It was basically the town donating their personal money to protect them basically you know and that was I think the state did allow some funding, but I mean it wasn't enough to make a difference. If a truck went down that truck's gone until we can save up the money or get a grant or figure out something to fix that truck. I mean we were living year to year as a department you know and that depended on the size of the department and the size of the town. (FF-R-048)

While rural first responders often expressed frustration at having to plead for funding or rely on fundraisers, they also recognized the importance of having a positive public presence for continued support of their work, whether that support is through local taxes or fundraisers. 
Many rural first responders also noted how they often struggled to even provide basic gear and tools for their personnel with the little funding they did receive, making access to technology secondary in many cases.

Normally you know in a lot of these places the stuff is held together by what the guys do in the station. They're not going to pay for a new light bar because a tree fell and hit the light bar and broke it so now you're running with a broken light bar but if you fix it in the station nobody's going to say anything you know so you fix that stuff, you get it going. Same with people will put their own tools, people go buy their own organization for the maintenance. They'll take their own box that they pay 10 bucks for at Target and they'll bring it in and put everything in there you know so it's organized and easy to get to, help everybody out. You see us just working with it you know making it work but nobody really sees that unless they are told or are shown because they just think oh that's the way we paid for all that. You know we pay your salaries, we pay for all of that. No, we pay for like we pay out of our own pockets for a lot of this stuff, so you know that's just something that we do. If we need it we'll pull money together and we'll do it you know. (EMS-R-018) We got a couple of guys don't even have gear and well until they just got some wildland gear but at a structure fire, they can't go to a structure fire. They can show up on a car wreck you know we've got guys here that are you know it's getting to the point where we've got to get some more gear but you're talking just the coat and pants alone are about \$3 500 that's not including boots, that's not including helmet, that's not including gloves you know, that's not including you know radios, you need hand tools, flashlights you know I mean there's a lot of hand tools that would be nice to equip every guy to have you know just for breaking glass you know but we have to have everything up to code. We can't just go down the hardware store per se and get a hammer you know to do this and that. Would it probably work? Yeah but inspection wise we got to have everything you know the fire tools that work better you know for our stuff. (FF-R-048)

All the radar I've bought have all been used. A new radar is about $\$ 2100$. I haven't paid more than $\$ 400$ for a radar unit. It costs me $\$ 70$ to get it serviced so less than $\$ 500$ I got a perfectly good radar unit and it's not shiny and brand new in the box, but you know what it comes down to function... (LE-R-048)

Rural first responders often have to buy their own tools, buy used equipment, or use old and/or out of date gear and materials. This often goes unnoticed by the public, who believe they adequately support their first responders, whether through fundraisers or taxes.

In addition, codes, certifications, and training required for first responders and their gear and tools make things more expensive (as with the example of hammers noted above by a rural fire fighter) and often unattainable.

My long-range planning is really what I spend a lot of time on because it's hard to determine, again, with our transient volunteers, again, through no fault of their own, what are their needs going to be. How do we need to make them successful in our organization? What classes are going to be available and at what cost? Classes are getting more and more expensive. We were just talking this morning. There is a class-- we're getting our last guy through it, which as we've gotten everybody else through, was 100 
bucks just to-- the tuition to get into class. That doesn't include the supplies, and hotel, and everything to get through it. But that class is now 500 bucks. (FF-R-019)

The reason why we're not going to get recertified [for stun guns] is just for our small agency it's about \$2 000 per recertification because each one of those little cartridges are about $\$ 25$ a piece and you have to have two cartridges per recertification and you multiply that by 20 something or 30 something people it's a ton of money. (LE-R-048)

Many rural first responder departments and agencies do not have the financial resources to supply their staff with gear, tools, and/or education to meet state and federal requirements, potentially putting them in danger or disqualifying them from working.

The lack of financial resources to adequately support rural first responder departments and agencies means that having access to up-to-date gear and tools is their first concern. Even when asked what technology they would like to have for incident response if they could have anything they wanted (see Appendix B for interview questions), participants responded with the basics; not the new technology their urban counterparts were likely to list. New technology is rarely mentioned as something they want or need, since it is often out of their reach.

First and foremost, l'd ask, I want all my firemen to have brand new gear. I want them safe. I want well we've got a couple of the trucks that we need updated. Those would be the first things and then from there it would be the tools. It would be jaws, it would be just new hand tools you know whether it's Halligan's, whether it's you know, just-- I mean anything you know-- just seat belt cutters, just stuff that you know-- we could equip all of our guys that way we're not searching in trucks going, "which truck is out again," you know everybody's like, "okay I've got mine right here, we're good," you know-- just that way our new SCBA's, our air masks. (FF-R-048)

I know that little counties like [county redacted] to the south of us or [city redacted], have they have one dispatcher on duty. They have no money. Their CAD system is Microsoft Word. A lot of times they just write stuff on a tablet and then type it into a word processor later and enter the times that they looked at their watch to get the times. They can't buy any of this stuff. But they have crime there, and they have people that get sick there, and heart attacks, and all of that kind of stuff. So where are all of these different comm centers supposed to go to get their money? It's all the user agencies, the taxpayer money now. I don't have a lot of confidence in our political structure that we have. (COMMS-R-002)

Similar to the 911 dispatcher quoted above, some first responders expressed a lack of "confidence" in the politics related to funding, and frustration at how this affected their work. As the fire fighter below notes, being "so underfunded" can put them at risk, which may influence their willingness and ability to do their jobs.

And it is like when I come home from my main job I-- sometimes it's not that I don't want to go out and do the work, fight the fire you know, work an extrication, something job related, it's the BS in politics that go with it. It scares me being out here as a first responder because we are so underfunded and limited in our resources from gear to technology. (FF-R-049) 
This lack of trust in budgets and the politics surrounding them resonates with the findings in the larger dataset, where first responders from across the U.S. articulated similar concerns about their budgets. One difference, however, is that in the larger dataset first responders spoke about how budget issues had an impact on their ability to buy and access new technology, whereas in the rural data, they spoke about how budget issues influenced their ability to buy basic gear and equipment, and even how it might put them in danger.

While rural and urban first responder departments and agencies all have budget concerns, there are issues that are unique to the rural environment, including the ways in which departments and agencies are funded. Many operate with the bare minimum and are unable to even provide access to basic gear and tools. The financial burdens they face seem different than those of their urban counterparts. Most important to them is having adequate and up-to-date gear and tools, not new technology. Technology such as license plate readers, for example, were never mentioned in the rural environment. The cost of this technology, and the statewide systems that they rely on, are not even on their radar. Even a nominal fee might be more than a rural department can afford. While budgets in urban areas may be less than they would like, the financial burden seems different for rural first responder departments and agencies.

\section{Haves and have nots}

As previously noted, the rural context matters when considering communication and technology. There is not one monolithic "rural" context, especially as relates to financial resources. All rural is not poor and all poor is not rural.

We're sitting in the million-dollar addition that we had to build because we were no longer getting volunteers from the town. And we were having guys coming here from [city redacted] and [city redacted] sleep in bathrooms because there was no place for them to stay here. Because prior to that, everybody had a house relatively close to the fire station. They used to respond here and grab a truck. Well, nobody lives in town, and we're still getting calls, so--. (FF-R-019)

There are some rural areas that are quite wealthy, depending on their context, with very different budgets for first responders. Rural areas with high tourist populations (and the funding that comes from tourism) have very different financial resources than other rural areas, in some ways creating a system of rural "Haves and Have Nots". For example, many popular resort destinations for skiing, hiking, or other outdoor activities are in rural areas. They are often characterized by million-dollar mansions and high costs of living. This means that many rural first responders cannot afford to live in the area where they work. Some first responders choose to leave when they cannot afford to live there, however wealthy rural departments can do things to mitigate this, such as build facilities for their responders, something many rural departments cannot imagine doing.

First responders recognize this disparity, and what it means for first responders-that some have access and others do not.

Honestly, what it comes down to, we all got to go to it, so we got to find the funding so that we can get there and it'll be and it'll work, because there's going to be some small counties in this state that can't afford to do this, and that funding's got to be there for them... And that's what we have you know, they went to a new system and we didn't because it wasn't talked about, planned financially, or any other reason to plan and then now, the ones with the most money [that are spending on] the technology get farther 
and farther away from those who can't afford it, or have the knowledge, I mean they may not even have the -- I wouldn't be surprised that there are some [city redacted] 911 centers that have no idea about [Next-Generation 911]. (COMMS-R-020)

... you got districts in this county, like us, who are pretty well funded. You get districts in this county, like [city redacted], they are completely volunteer. Their budget is, I mean-we give them our used equipment because they need it. They have no money to spend on anything, so how are you going to apply technology evenly across even as small an area as our county and make sure that it benefits everybody? (EMS-R-008)

I was at a training deal extrication class and one of the instructors was the [city redacted] Fire Department... he [the instructor] goes, 'it's funny listening to you guys talk you know you're going gosh I wish we could get a truck you know, I wish we could get you know jaws.' Get this, he goes, 'we got guys complaining because their gloves are a month old,' and I looked at him and I said, 'we got gear that's been out of date for ten years.' (FF-R-048)

In the quote above from fire service participant 048 , he is relaying a story from an extrication class he attended. $\mathrm{He}$ is from a district where they struggle to provide basic equipment, while the instructor he is speaking to is from a well-funded district where some responders complain "because their gloves are a month old." Both recognize the financial inequities that exist in their respective rural areas, as do the other participants quoted above. In many cases, departments have to utilize old, used, and possibly out of date gear and equipment, while others are able to purchase and provide the latest technology and equipment. This is certainly an inequitable situation, and one that may put some first responders at greater risk than their wealthier counterparts as they respond to incidents, along with the public they serve.

\section{Personnel resources}

Many rural first responders spoke about a variety of different ways in which human resources were a major challenge for them. One rural firefighter noted that "Financial and staffing are the two biggest [issues]" (FF-R019) they face. The personnel issues faced by rural first responder agencies and departments are often related to broader financial issues. Smaller budgets make recruiting, hiring, and maintaining staff much more difficult. It is almost impossible to attract and keep personnel when the pay is low, and when the work is not what they expected, and departments often suffer from not having enough personnel to adequately staff their shifts. In addition, funding does not always exist to hire specialized personnel. In some cases, this means that one person must fill several roles. In other cases, the specialized training they need due to the types of seasonal and geographic incidents they face is extremely difficult to attain from a financial resources perspective.

Recruiting, hiring, and maintaining staff is often difficult in the rural environment. Sometimes it is difficult to even find people interested in applying as first responders in rural departments.

Well first off you get them here and second off you keep them here. (FF-R-048)

So as to why people aren't applying, whether that's part of it. In our local community, it is a high cost of living area. We do get a lot of people that come here, realize they're not going to be able to afford to buy a home or get out of the apartment. Put in a couple of years and leave to go to a lower cost of living or bigger city. We don't have all the areas of operations or responsibilities that a true city would have. We don't have a vice unit, 
and a motor unit, and a traffic unit. So you may come here, and you may be a patrol guy for 20 years, and there's nothing wrong with that, but if that's not what you think you're going to do with your career, or that's not okay with you, it's not going to work out. (LER-019)

As noted by the participants above, hiring and keeping first responders is often a challenge. Once they do apply and are hired, they often only stay for a few years, and attrition is a major problem for rural first responder department and agencies. As noted by the EMS participant below, most of them end up leaving after a few years.

And those are generally younger people, and they generally have a more flexible schedule. They generally have less home responsibilities. They're generally more eager to work on trying to get a full-time job. So we home-grow a lot of those people into paramedics here. Not all of them. In fact, probably the majority of them end up going someplace else after doing a few years here. (EMS-R-007)

Yeah, and [the high turnover rate has] always been that way. The guys get here, they put in four or five, they get some training and experience, and then they decide it's time to start looking somewhere else. Some of them recognizing, as they mature, they gain knowledge and wisdom. As an adult, and actually start thinking about retirement, and where they're wanting to be, and whether it's a pension, or a 401(k), and then the work situation and overtime, and how much they can make. That they're young enough, that the time is now to make that decision to go somewhere else. (LE-R-019)

Rural first responders may leave when they realize that their rural jobs do not and cannot provide them with what they want financially, or when they realize that they will not be able to move up to do the type of work they are most interested in. Younger responders often use employment in rural areas as stepping-stones for their careers, leaving after only a few years. This means that a department has spent time and money training them, only to lose them down the road, depleting their resources even more. It may also be a contributing factor to the differences in years of service between the rural dataset and the overall dataset, where the number of rural first responders who leave in the first five years (17.74 \%) is over 50 percent more than in the overall dataset (10.99 \%) (see Sec. 3).

For many rural departments, this means staffing levels are always a problem, and they rarely have sufficient numbers of staff to cover shifts.

...our biggest problem is limited number of people. (FF-R-048)

We got really short several years ago. We used to run day shift, evening shift, and night shift like everybody else. We got really short and we were looking into how we can cover more time with fewer people... (COMMS-R-019)

In part, this is due to less people applying to be first responders in rural areas, in addition to the high attrition rates they face. In other instances, staffing issues are a result of the seasonal nature of the work, as discussed in a previous section.

It's a nightmare to staff because how do you staff full-time, qualified people when your call volume in May might be 200 calls in a month, and my call volume in January is 700 
calls in a month. So I have to be able to expand and contract responsively, because you can't build the church for Easter Sunday [laughter]. Taxpayer's money, it just doesn't work. It's not sustainable. So I have two paramedics in every ambulance, and then in the winter, I hire EMTs who do seasonal work, and have some other job as their main job. You have to get very creative about staffing around here. (EMS-R-008)

This often forces rural departments and agencies to "get very creative" with the personnel resources they do have and how they use them.

Another issue faced by many rural departments is their inability to hire specialized personnel. There is rarely enough money to be able to hire an information technology (IT) specialist, a web/social media person, or even human resources personnel. One result is that one person is often tasked with doing a variety of different types of work, from human resources to IT to patrolling.

Being in the area we are, I do everything. I will handle everything from a homicide to hanging Christmas lights. And it could be all in the same day. (LE-R-017)

Yeah. So, obviously, I have a lot of administrative work because I am the HR manager. I'm the fire chief. I'm also our IT guy. So I do all of that. (FF-R-019)

Often, those having to cover these different tasks do not have specialized training, for example in IT or in web design, meaning that those areas often suffer from a lack of expertise and time. In addition, as previously noted, many rural departments do not have specialized staff positions and units, such as vice or detective, and often need specialized personnel such as wildfire or search and rescue experts. However, largely due to budget constraints, it is almost impossible for most rural first responder departments and agencies to provide for the various types of specialized personnel needed.

\section{Rural volunteers}

Many rural areas rely on volunteers to provide adequate staffing and incident response. While this is more prevalent for rural fire and EMS departments, we also heard of volunteer issues with some law enforcement departments. As noted above, rural first responder departments and agencies in general have trouble attracting and maintaining paid personnel. Similarly, volunteer departments and agencies have difficulty attracting and keeping volunteers, often for the same reasons: pay and advancement.

We also live in a resort community, and we have a lot of transient population. And so as a volunteer comes in here, and the society expects them to have the same certs as a paid individual, even though they're volunteers. And we live in a high-cost area, so they have two or three jobs in order to maintain a minimum standard of living. On top of that, they're now required by the public to have the same certs as a paid guy, which takes time away from their job... the life expectancy of a volunteer to maintain that internal and external standard is really, really difficult. (FF-R-019)

The amount of time a volunteer stays in their position is low, with many leaving once they recognize the demands on them for training, certifications, and time. In addition, the seasonal nature of some rural areas is problematic for keeping volunteers given that much of the population is "transient" and leaves after the season. This means that volunteers themselves might leave, or that call volume goes down dramatically meaning that volunteers have less work and may need to leave in order to earn "a minimum standard of living." 
Another similarity to paid rural departments and agencies, is the way that many use volunteering as a steppingstone to a paid career.

I am career now. I used to be, I used to volunteer here. (EMS-R-018)

Back in the day, when I started, it was more of the community. You are a part of your community. It was a way to give then your community, and so it was that volunteer community fire department. Nowadays, because of all the challenges that we've discussed there, and that change in the society, the only volunteers we're getting are the young college-age level kids that want a fire job, and so they're using this as a gateway to get experience and get in. And then as soon as they have the opportunity, they're gone. So our average is about three to five years. (FF-R-019)

In order to garner experience, many first responders begin as volunteers, such as the EMS participant above, and then move to career, paid positions, leaving volunteer departments and agencies with the costs for training but without a stable workforce in the end. This, along with the aforementioned younger responders using employment in rural areas as stepping-stones for their careers, may also be a contributing factor to the differences in the initial five years of service between the rural dataset and the overall dataset (see Sec. 3). In general, volunteerism is declining, and many rural first responders spoke about the "steady decline" they have seen, both at home and across the country.

Volunteerism across the country, we know, is plummeting. The expectancy or the expectations of firefighters continues to astronomically grow, and so it's becoming more and more difficult to have volunteers who have time, commitment, and ability to do what's expected. And then with all those expectations comes enormous cost and trying to keep up with everything. (FF-R-019)

Well one thing is that across America, about $75 \%$ of fire departments across America is volunteer. I can tell you that since I've been in the fire service, the volunteer fire services are a dying breed. We've seen a steady decline in the amount of volunteer fire service. I remember when my dad was a chief we probably was 400 or 500 members strong. People were able to be able to leave their jobs and now, it's just, it's dwindled away, the way we, we get a working structure fire today, we may see 25 or 30 people there. So during the daytime. At nighttime, we might see 125 or 150 people at a nighttime fire... We're having to do cross training things, like years ago when I was growing up when my daddy was the fire chief, the fire department had no responsibility on medical emergencies. The ambulance service takes care of that. (LE-R-053)

This decline in volunteerism is due to many things, including the increased requirements for volunteers.

And I ain't saying training is bad but there's a difference between volunteer and paid people you know... We're at work all day and then we have to go and take our training at night 2 to 3 times a week you know from 6 to 10 at night and then come back to your families or whatever, I mean it don't go over very well for some you know. (FF-R-047)

Often, in order to meet these increased expectations and requirements, volunteers have to spend their own time and money getting training or certifications that allow them to volunteer. 
Another reason volunteerism may be down is that employers are no longer as likely to let employees leave to respond to incidents. In part, this is due to the fact that volunteers do not always work in the town where they live and/or volunteer.

And we understand that they have to work to take care of their families also. So, some we can get, they'll leave the job, and their job understands. So, it kind of weighs out for them. But some of them don't work in [county redacted], and they can't respond. So, it's a 50/50 chance that you get them. (COMMS-R-010)

But during the daytime, it just seems like owners of businesses, and they just don't allow their employees to be able to go anymore. (LE-R-053)

You're no longer pulling your volunteers from your community because of the change of society. It's those who want to. So they might live in [city redacted]. They might live in other towns. So you have very few of our volunteers live in town. They have to commute here for the full shift. (FF-R-019)

One result is that volunteers today often do not live in the community in which they volunteer. They often live and/or work somewhere else, and employers are less likely to understand and "allow their employees to be able to go anymore." Or volunteers have to commute in order to volunteer, making it more difficult for them to respond to an incident in time.

Finally, rural first responders spoke about the relationships between paid and volunteer first responders.

It depends really on who you are. If you are here and show an interest in helping them and teaching them and working with the volunteers they will share respect back to you on any given scene. You know it's all in the way you communicate with them. You know you yell at them, you get worked up with them or do you just calmly talk to them even in the worst situations because in truth they don't even have to be there so you know when they get the call at night they can choose rather or not they're going. We can't choose and that's what comes with the job so you need to understand that when you get out with these people. They're out here and every finger they lift is a plus for you. It's one finger you didn't have to lift so it's all based on how you talk to them I think. If you come over here, make yourself seen you know in classes with the EMR they'll know who you are out on calls. They're more likely to help you out. They're more likely to jump in the back and listen to you when you say hey, will you put your finger here? Will you grab me this? Grab me that? If you show an interest in them they'll show an interest in you and just don't act mean to them. I mean a lot of people in this business will say you're a volunteer, get out of here but coming from a volunteer background they're necessary. I mean very necessary so you got to have them. (EMS-R-018)

As the EMS participant noted, it is important to develop relationships amongst career and volunteer first responders. Those relationships are magnified in rural areas, where good communications can improve the relationships. 


\section{Infrastructure resources}

When thinking about the infrastructure required for rural first responders, it is necessary to consider the basic physical and organizational structures and facilities they need in order to accomplish their work. This can be buildings, roads, hospitals, communication coverage, and other related infrastructure first responders need to support incident response. Rural first responders often do not have department phones, emails, or websitestheir communication infrastructure is often minimal. As noted in previous sections, rural first responder departments and agencies often have problems with communication and coverage, due to a lack of radio towers and signal stations, and several spoke about how communication companies do not want to invest in rural areas, leaving them without much needed coverage. In certain rural areas, the lack of GPS can impact location navigation during incident response. Additionally, it is notable that occasionally there is no actual "building" that houses rural first responder departments, especially a totally volunteer department.

I'm getting some hot spots for our computers and stuff in the car but even here the county and stuff is just not what it needs to be. We have the community to actually send us hot spot information as far as wireless churches, businesses and stuff like that and I'll send that list out to the deputies and they'll go sit in front of the business and use their wireless that's hooked on to you know fiber optic or something that'll be a lot higher speed but I mean ideal that's what you want. You want your radios to work and you want your cell phones to work all over the county. I mean that's pretty much it. I think the infrastructure [is] there, it's just a matter of the-- having the capability of doing it wherever not having to worry about you know. We did a missing person scenario down towards [county redacted] in the national forest and nobody's radio worked. (LE-R-048)

That technology is available, it's just a matter of do you have the money and the infrastructure to do it and the bandwidth to do it? (FF-R-051)

Rural first responders in this study spoke often about the need for basic infrastructure, like radios and cell phones that work "all over the county." While some of this is about access to the technology itself, it is also about how well developed and supported wireless and other communication networks are in rural areas. Others spoke about buildings that are "bare bones"

Our budget certainly doesn't support a million-dollar building. And it's obviously not a Taj Mahal. We don't have marble. We don't have all this stuff that really costs a lot of money. This is bare bones, drywall and wood addition. (FF-R-019)

Some rural departments operate in buildings that are often insufficient for their needs and do not have the means to improve these, since public funding is limited.

Another example is the lack of auxiliary first responder services, such as hospitals and other medical facilities and resources found in rural areas, and the amount of time needed to access them.

For example, the LUCAS ${ }^{4}$ devices were real expensive for us down here but it was a necessity because we're taking people 45 minutes [to a hospital], so that was a necessity (EMS-R-018)

\footnotetext{
${ }^{4}$ LUCAS is an automated chest compression system for administering cardiopulmonary resuscitation (CPR).
} 
In an urban environment, first responders might have access to a multitude of different hospitals, while in a rural environment they might need to drive 45 minutes to get to the only hospital in the area.

Insufficient infrastructure and the inability to improve it is something that characterizes many rural areas, along with the first responder departments and agencies located there. The NPSBN is designed to address issues related to communication coverage for rural first responders, but there are also other pieces of infrastructure missing in rural areas that influence their ability to accomplish their primary task of protecting lives and property.

\section{Discussion}

Rural first responders face problems and challenges specific to the contexts of their work, and as a result the technology they need may be different than what is needed in other environments. "Indeed, rural consumers have unique public safety needs, from devastating forest fires, floods and tornadoes, to concerns related to military and border facilities" [1]. Rural first responders, similar to those in the full dataset, emphasized that what they really want is for their current technology to work better, rather than new technology. As noted in Volume 1: "Participants consistently emphasized wanting their current technology to work. New technology is not always perceived as the right answer to the problems they face. Instead, they overwhelmingly spoke about how the improvement of current technology is what they want and what they believe will be most helpful," [2]. The same is true for rural first responders. When asked a specific question about their "wish list," rural first responders generally wished for current technology that worked better. Rural first responders know what works for them, and what would be most helpful as they engage in their primary responsibilities. They are interested in technology that will help them do their jobs better, such as a better radio system that worked across their response area.

I mean I think if I had a wish list for the Sheriff's department it would be to have a better radio system as far as its reach, so it didn't have areas in the county that didn't have any cell service or any radio service. (LE-R-042)

For most first responders, their technology wish list means having current communication tools that work better, and that work in more places.

It is difficult to imagine how rural first responder departments and agencies that do not have basic gear will be able to purchase and access new technology. As many noted, it must be affordable, and they do not see new technology as within their reach-something that was also present in the larger dataset.

It has to be affordable, and that's the challenge. Of course, they're loosely related. I mean, there are companies out there that sell all this stuff, but it's never achievable for us. We'll never be able to spend $\$ 10000$ on a radio. We have a hard enough time spending-- right now, I mean, our radios are costing almost 4 grand for radio. And that's why we have older radios because we can't afford the new stuff. (FF-R-019)

If you got unlimited resources you can make phenomenal technology and I can come out here and put up digital towers, put high towers up in this county and have crazy good you know I can make it so that you know we can connect computers to it and everything else. I ain't got that money so the question is how good can you have for what you can afford? You know you try to make the most of what you have and I don't mind buying used stuff... 
If it's good you use serviceable equipment. You save a ton of money and get more for your money and come out ahead on that, you know. (LE-R-048)

Rural first responders recognize that new tools and technologies are out there, but do not see them as realistic in their contexts, either in terms of their geographic or financial context.

Some rural first responders spoke specifically about the need for usability in any new technology developed to "help" them, and for the need to understand their context when new technology is developed.

Well... unless there's input from the users in developing and building it... that's the challenge that I see because if you're not sitting in that chair, dispatching, taking calls, well we can give that to communications as always a--but as you can see out here they have 5 computer screens in front of them. What does the technology do? Does it increase their workload, their responsibility, their-- and with responsibility comes liability? Does it increase that or does it decrease that? Or is it kind of a neutral that this is going to be something new but it's going to help you take some of that workload off but it's going to replace that so is it going to be a neutral or is it going to be something that's going to increase their workload? (COMMS-R-016)

Well, unfortunately, as a volunteer, we have WhenToWork. We have emergency reporting. We got their training program they log into. There's a state cert system. So, unfortunately the devil's in the details. As a volunteer, you could actually become inundated with apps and all these different log-ins because there is no one program that solves everything for volunteers. So that's actually a detriment to our program, are the apps and the availability of all these technologies because they don't interface with each other. Some of them only do iPhones. Some of them only do the Android stuff. So even that's a problem. (FF-R-019)

Questions surfaced such as whether or not technology increases or decreases workload, whether or not it comes with additional liability, or even whether or not new technology might replace them and their jobs. Other times, participants noted how technology actually made their work lives more difficult, as with the multitude of log-ins needed and how they do not always work on all platforms, creating additional difficulties especially for volunteers. These questions and concerns all resonate with the larger dataset, where many participants had similar concerns.

Overall, the five technology opportunities identified in Volume 1 for the PSCR R\&D community hold true for rural first responders as well [2].

Interoperability - The ability of a system or a product to exchange and make use of information with other systems or products without special effort on the part of the users-data integration and sharing from radios to radios, systems to systems, devices to devices, and departments to departments.

Reliability and connectivity - $100 \%$ connectivity for radio, cellular, and wireless networks in spite of geography and topography-urban canyons, subways, basements, or other dead zones.

Accountability and location - Development of technology that provides for accountability and location tracking of the crew, units, 911 callers, and building occupants. 
Maintenance, technical support and training - Minimization of the burden and costs of the associated maintenance, technical support and training of technology imposed on users and departments.

Organizational policies and administration - Facilitation and promotion of technology adoption by first responders through policies, procedures, and administration to minimize barriers and hindrances to use while supporting first responders' primary tasks.

These opportunities are what first responders, including rural first responders, see as the most important for developers to address.

However, developers must recognize the unique nature of the contexts in which rural first responders work and the specific needs they have, and not develop one-size-fits-all solutions. For example, rural first responders questioned the need for additional technology in their contexts.

I find often, technology drives us in directions that we aren't necessarily ready to go yet as a small organization. (EMS-R-008)

Well, I mean, I can't keep up. One of the complaints I get is that we're trying to use technology to fix all of our problems. And there's some truth to that and I don't like it.

(FF-R-024)

In addition to questions of financial feasibility, there is also a recognition that new technology cannot solve all problems faced by rural first responders. While rural first responders often questioned the usefulness and feasibility of new technologies, they do provide some overarching thoughts about what they do need and want. In listening to the voices of rural first responders, the following technology needs emerged as necessary to their work:

- Better coverage for radios, cell phones, computers, and other communication tools

- Better location capabilities to find people and "addresses"

- Tools for rural-based events to help with area-specific types of incidents (whether seasonal or topographic)

- Tools equipped for the rural expanse to help mitigate the size-distance issues

- Reasonably priced communication tools

- Access to basic equipment and gear before they can buy "newfangled" technology

- IT support and help

Moving forward, consideration of the context of use, in this case the rural environment, should drive technology improvement and development for mission critical voice, location-based services, and data analytics [13].

\section{Acknowledgements}

NIST would like to thank the many first responders who graciously gave their time and input for this project. The authors would also like to thank Kevin Mangold of the NIST Visualization and Usability Group.

\section{References}

[1] Bloomfield, S., Rural Network Deployment is Key for First Responders. Broadband Beat: Thoughts and Perspectives from Shirley Bloomfield. April 22, 2019. https://ceoblog.ntca.org/rural-networkdeployment-is-key-for-first-responders/ (Retrieved September 2019). 
[2] Choong, Y, Dawkins, S., Furman, S., Greene, K.K., Spickard Prettyman, S., Theofanos, M.F. Voices of First Responders - Identifying Public Safety Communication Problems: Findings from User-Centered Interviews. Phase 1, Volume 1. NISTIR 8216 (2018). https://doi.org/10.6028/NIST.IR.8216

[3] Choong, Y., Dawkins, S., Greene, K., and Theofanos, M. Incident Scenarios Collection for Public Safety Communications Research: Framing the Context of Use, NISTIR 8181 (2017). https://doi.org/10.6028/NIST.IR.8181

[4] Cromartie, J. and Bucholtz, S. Defining the "Rural" in Rural America. Rural Definitions, USDA, Economic Research Service, August 2019. https://www.ers.usda.gov/amber-waves/2008/june/defining-the-ruralin-rural-america/ (Retrieved September 2019).

[5] Crooke, C. Women in Law Enforcement. U.S. Department of Justice, Community Policing Dispatch (2013). http://web.archive.org/web/20190716200943/https:/cops.usdoj.gov/html/dispatch/072013/women in law enforcement.asp (Retrieved September 2019).

[6] Data USA. Dispatchers. https://datausa.io/profile/soc/dispatchers\#demographics (Retrieved September 2019).

[7] Dawkins, S., Choong, Y., Theofanos, M., Greene, K., Furman, S., Steves, M., and Spickard-Prettyman, S. Voices of First Responders - Examining Public Safety Communication Problems and Requested Functionality, Findings from User-Centered Interviews, Phase 1, Volume 2.1. NISTIR 8245 (2019). http://doi.org/10.6028/NIST.IR.8245

[8] Evarts, B. and Stein, G.P. U.S. Fire Department Profile. NFPA, March 2019. http://web.archive.org/web/20190926134416/https://www.nfpa.org/News-and-Research/Dataresearch-and-tools/Emergency-Responders/US-fire-department-profile (Retrieved September 2019).

[9] Federal Emergency Management Agency (FEMA) Regions, https://www.fema.gov/risk-mappingassessment-and-planning-risk-map (Retrieved September 2019).

[10]Hackos, J. T., \& Redish, J. (1998). User and task analysis for interface design. (pp. 23- 24). New York: Wiley.

[11]ISO 9241-210:2010: Ergonomics of human-system interaction -- Part 210: Human-centred design for interactive systems, ISO, Geneva, Switzerland, 2010, http://www.iso.org/

[12]National Registry of Emergency Medical Technicians. The National Registry Data Dashboard. In The National Registry (April 13, 2017). www.nremt.org/rwd/public/data/maps (Retrieved September 2019)

[13]Public Safety Communications Research. Research portfolios. https://www.nist.gov/ctl/pscr/researchportfolios (Retrieved September 2019).

[14]Ratcliffe, M., Burd, C., Holder, K., and Fields, A., Defining Rural at the U.S. Census Bureau, ACSGEO-1, U.S. Census Bureau, Washington, DC, 2016. https://www2.census.gov/geo/pdfs/reference/ua/Defining Rural.pdf (Retrieved September 2019).

[15]Reynnells, L., What is Rural? Rural Information Center (U.S.) Beltsville, MD: USDA, National Agricultural Library, Rural Information Center. Revised May 2016. https://www.nal.usda.gov/ric/what-is-rural (Retrieved September 2019).

[16]Theofanos, M., Choong, Y., Dawkins, S., Greene, K., Stanton, B., and Winpigler, R., Usability Handbook for Public Safety Communications - Ensuring Successful Systems for First Responders. NIST Handbook 161 (2017). https://doi.org/10.6028/NIST.HB.161

[17]U.S. Census Bureau. New Census Data Show Differences Between Urban and Rural Populations. American Community Survey: 2011-2015. https://www.census.gov/newsroom/pressreleases/2016/cb16-210.html (Retrieved September 2019). 
[18]U.S. Census Bureau. Rural America. https://gisportal.data.census.gov/arcgis/apps/MapSeries/index.html?appid=7a41374f6b03456e9d138cb014711e0 1 (Retrieved September 2019).

[19]Yin, R.K. (2003) Case study research: Design and methods ( $3^{\text {rd }}$ ed.). Thousand Oaks, CA: Sage. 


\section{Appendix A: Detailed methodology}

The research design for the project began by developing research questions (as stated in Sec. 1) that would guide the work during the course of the project. This important formative stage of the research serves as a foundation and provides a focus for data collection and data analysis. Qualitative research is iterative in nature and focuses on the importance of participants' voices and perspectives throughout the research process. The research process consistently returns to the research questions to inform future elements of the process such as data collection and data analysis. Data collection and data analysis were conducted in tandem and occurred iteratively, each informing future iterations. The project is cross-sectional including input from rural participants from all public safety disciplines, from a variety of ranks and levels, and from a variety of geographical areas. It is also constructivist in that the focus is on how rural first responders construct and conceptualize their worldsbased on their individual understandings as well as based on shared meanings and social constructions.

A case study approach was used, which Yin argues is appropriate when exploring "how" questions where contextual conditions are relevant to the phenomenon under study, and where the behavior of those involved in the study is only observed [19]. For this project, the phenomenon of study is experiences of rural first responder communication, which cannot be understood outside of the rural first responder context.

In the following sections, we present details related to sampling, data collection, and data analysis.

Sampling strategy

The sampling strategy for the larger project included ensuring representation of first responders from all four domains: 911/dispatch, emergency medical services, fire service and law enforcement [2]. Geographic diversity was also important since the public safety issues faced by first responders may be different based on geographic location. Across the U.S., first responders from urban, suburban, and rural areas were included, to ensure that communities of different sizes and different economic realities were represented. In addition, in order to be representative of the first responder population across the United States, attention was paid to first responders at different jurisdictional levels (local, county, and state) and different ranks and levels, recognizing that their work, and the technology needed to accomplish that work, might vary. This strategy allowed for insight into the variety of experiences faced by first responders across the U.S. and ensured coverage of both typical and unique experiences.

This report focuses specifically on the data from rural first responders. Of the 193 first responders interviewed for the larger project [2][7], 63 (32.64 \%) operated in what we defined as rural areas of the U.S. The 63 rural responders collectively represented all four first responder disciplines.

\section{Data collection instruments}

A semi-structured interview protocol was developed for use in the larger project. The protocol questions grew out of the problem and purpose statements and the research questions, input from subject matter experts (SMEs), the literature, and background knowledge of the first responder community. An iterative approach to refining the data collection instruments was utilized in order to ensure that language, questions, and concepts were appropriate and would elicit valuable responses that would allow the research questions for the project to be answered and addressed. Pilot interviews with two or three first responders in each discipline were conducted as well and several subject matter experts reviewed the instruments to assess content validity and to ensure all relevant and related concepts were addressed by the instrument. Several content and subject matter 
experts who provided input and feedback came from rural areas. This ongoing review and refinement of the protocol is consistent with the iterative nature of qualitative research. The protocol questions are listed in Appendix B.

The interview protocol included a short demographic form that also included two additional questions related to participants' ease and comfort with technology (see Appendix C). The demographic questionnaire was short to allow maximum time for the interviews. Since usability focuses on users, their tasks, and the context of use, protocol questions fell into two main categories: context of work; and perceptions of and experiences with communication and technology (see Appendix B). Questions about context of work included descriptions of: their overall job, tasks, and daily routine; relationships with other people (their direct colleagues, other first responders, dispatch, the community, and the media, for example); and what work is like-both in and out of the station or specific work environment. The protocol and all relevant documents were approved by the NIST Human Subjects Protection Office (HSPO) and the Office of Management and Budget Paperwork Reduction Act.

\section{Data collection process}

As discussed earlier, the data for this rural analysis are part of a larger dataset of in-depth, one-on-one, semistructured interviews with first responders across the U.S. Most interviews took place in the workplace, a police station or fire station, for example, in either a group gathering area or in a private office or conference room. Each participant was provided with a copy of the Information Sheet about the study, and was informed verbally that:

- their participation was voluntary,

- they could stop at any time without penalty,

- they could decline to answer any question(s),

- all data would be de-identified,

- the interview would take approximately 45 minutes, and

- the study had been approved by the HSPO.

Participants were asked for permission to audio record the session. Occasionally, participants were called away for incident responses, which resulted in shortened or truncated interviews.

Given time and resource constraints and the importance of performing in-depth interviews to hear first-hand from first responders, it is not possible to reach a large percentage of the rural first responder population. For the rural data, the sampling strategy resulted in an under-representation in EMS participants. In the public safety field, there is no such thing as perfect representation, because every place and station are unique in some way. Interviewing a wide variety of first responders, with a wide range of positions, responsibilities, years of experience, and other variables was intentionally pursued to address potential coverage and representation issues.

\section{Data collection challenges}

Collecting data from rural first responders responsible for day to day incident response and operations posed several challenges. A major challenge was simply gaining access to the first responders. Permission was often needed from multiple authority levels, or from specific public safety officials, in order to schedule interviews and start the data collection process for a given location. Those in positions of authority were protective of their first responders and their time, and often controlled access to them, and rightfully so. Their time is extremely 
valuable, and the team fully recognized that fact, knowing that their assignments and life-saving duties obviously take priority over interviews.

Another difficulty experienced during rural data collection in particular revolved around gaining access to rural first responder departments and points of contact. Making an initial contact with rural first responders was hindered by the fact that many did not have department phones, emails, or websites, often utilizing personal cell phones and emails for communication. As noted in Volume 1, in many instances, gaining access to first responders was dependent on referrals from personal and/or professional contacts, or on the use of snowball sampling [2]. This access issue was magnified, as well as challenges with logistics, for the rural demographic. Once contact was made, rural first responders were very interested in participating, noting how they often felt left out of research since they were so "small" and as a result felt that their voices did not matter.

In addition to being difficult to initiate contact, it was often difficult to physically access many of these rural areas, especially given some of the terrain and remoteness of the locations. From a time and resource perspective, data collection in these rural departments and agencies costs much more than data collection in metropolitan areas. These data collection challenges may be one reason why rural first responders represent an understudied research population, and another reason why it is such an important population to examine here.

Data analysis

The data consist of interview transcripts, demographics questionnaires, field notes, and analytic memos. The interviews provide an in-depth and yet overarching look at rural first responders and their work in their own words. All interview recordings were transcribed by an external transcription service; these interview transcripts were then used for the qualitative coding process.

In contrast to coding in the computer science and software engineering domains, qualitative coding is a process of labeling sections or chunks of narrative data capturing the essence and/or salient features to group, compare, and/or manipulate similar chunks. In essence coding is a process for reducing and/or reconfiguring data in an organized and meaningful way. Coding is the beginning of the analysis process.

The coding process in the larger dataset began with an a priori code list. The a priori codes are a set of labels based on the research questions, relevant literature, and an understanding of the communication and technology space in the first responder community. Interviews for this rural analysis had been coded previously in the work done for the broader project. Additional coding paid specific attention to characteristics and experiences that seemed unique to the rural environment. The question that focused this phase of the coding was: What makes this rural?

Two members of the rural analysis team began by reading all 48 of the rural transcripts to gain a holistic sense of the data. Each team member then coded two randomly chosen rural transcripts to identify codes specific to the rural dataset and to recognize where there was convergence and divergence among the researchers' coding and to use these points of intersection/difference to explore the data more fully. The team then met to discuss and operationalize these codes. Operationalizing each code consisted of providing the definition of the code, when to use it, when not to use it, and examples for each code. Each researcher then coded a subset of the remaining 46 transcripts.

Team meetings occurred regularly in order to ensure that the codes were being used consistently, and to identify additional codes as needed. As previously noted, the goal in coding the rural data focused on what made these participants, their experiences, and/or their environments unique. Ultimately, two broad ideas 
emerged as important concepts for analysis: Rural Geography and Rural Community. These were further explored for the ways in which they provided insight into first responders' experiences related to communication technology.

Validity and reliability

Qualitative methods require different approaches of providing validity than quantitative methods. Even similar terminology has different meanings. Table 3 below illustrates how qualitative and quantitative methodologies use the same terminology in different ways.

Table 3. Quantitative versus qualitative validity

\begin{tabular}{|l|l|l|}
\hline Term & Quantitative Definition & Qualitative Definition \\
\hline Significance & $\begin{array}{l}\text { The number that expresses the probability } \\
\text { that the result of an experiment could } \\
\text { have occurred by chance. }\end{array}$ & $\begin{array}{l}\text { Identification of trends or ideas in the data } \\
\text { that are not obvious, but which point } \\
\text { toward a new, emerging, and/or } \\
\text { interesting understanding of the data }\end{array}$ \\
\hline Reliability & The overall consistency of a measure & $\begin{array}{l}\text { The dependability of the process and } \\
\text { product of the research, which can be } \\
\text { provided through an inquiry audit or other } \\
\text { means of demonstrating consistency }\end{array}$ \\
\hline Validity & $\begin{array}{l}\text { The method of power analysis used to } \\
\text { detect a relationship }\end{array}$ & $\begin{array}{l}\text { The trustworthiness provided by } \\
\text { transparency in study design and process, } \\
\text { including the delineation of analytic } \\
\text { processes that are systematic and rigorous }\end{array}$ \\
\hline Sample size $(\mathrm{n})$ & $\begin{array}{l}\text { The number of samples necessary to reach } \\
\text { a certain statistical power }\end{array}$ & $\begin{array}{l}\text { The number of participants or cases } \\
\text { needed to reach saturation in the data }\end{array}$ \\
\hline
\end{tabular}

Qualitative methods generally rely on trustworthiness as a measure of validity. Trustworthiness consists of four different components: credibility; transferability; dependability; and confirmability [2]. Credibility refers to a belief that the findings are congruent with reality (specifically with the reality of the participants). This is accomplished through a variety of measures, including the use of:

- Well-established research methods (such as interviews and observation field notes),

- Triangulation (across time, person, location, and organization),

- Practices to encourage accurate responses from participants (such as informing them they can voluntarily withdraw or decline to answer a question at any time, and data are collected without identifiers),

- Iterative questioning (to insure consistent data from participants),

- Frequent debriefing sessions among researchers (to explore gaps in the process and/or product and insure exploration of varied and alternative ideas),

- Experienced investigators who are knowledgeable about the content and the population,

- Member checking (the use of participants and subject-matter experts to review research interpretations), 
- Detailed description of the phenomena under study and the use of participants' own words. In fields such as sociology and human-centered design, a thick description of a human behavior is one that explains not just the behavior, but its context as well, such that the behavior becomes meaningful to an outsider.

Transferability is about the extent to which findings from this study could be applied to other situations. In quantitative methods generalizability is built into the research design and occurs at the time the research is conducted. In qualitative methods, it is incumbent on the researchers to use rich, thick description of the research process, including a focus on the participants, to provide readers with a good understanding of participants and experiences delineated in the research. The detailed description of the methodological process promotes the transferability of research findings to the readers.

Dependability, or reliability in quantitative terms, refers to the likelihood that if the work were repeated in the same context with the same methods, and same participants, similar results would be obtained. In qualitative research, dependability is provided by ensuring transparency in the research process and providing detail about all research processes. This creates a model of the research that others can utilize as a "prototype" to conduct a similar study. In this report, specific detailed descriptions of the research design, data collection methods, tools, timelines, and analysis processes are provided.

Confirmability is about ensuring that the findings presented are based on the knowledge, beliefs, and experiences of the participants and not on what the researchers believe or prefer. Confirmability is about providing objectivity-in the data collection and in the data analysis. One key to this is recognizing researcher biases and pre-dispositions. The research team reflected about how the team's backgrounds and disciplinary training might influence their thinking about the project. For example, the sociologist/qualitative methodologist on the research team grew up in a family of police officers and fire fighters, and several members of her family continue the family tradition today. Her experiences and background knowledge were monitored so as not to bias the results. The team documented self-reflections in analytic memos as a technique to monitor biases and pre-dispositions. Another important component is the provision of detailed methodological descriptions of the decisions about the data collection and analysis in order to provide transparency in the process and in the product (the interpretations). This type of data audit trail provides a step-by-step guide to what was done, when it was done, how it was done, and why it was done. A 'theoretical audit trail' (the analytic process and how different tools were used to interpret the data) was also constructed. Together, the data and theoretical audit trails provide a strong foundation for confirmability of the research. 


\section{Appendix B: Interview Questions}

\section{Context and Beliefs of Work}

1. What is your job title?

a. If you were describing your job to someone who knew nothing about it (like to a kid, or someone from another planet), how would you describe it?

b. Tell me about your daily routine. How does your day begin?

i. If there isn't one, list the different kinds of things you do during the day.

ii. What's typical communication like for you during your work day?

c. What is it like when you are at the station?

i. Describe your relationships with other folks you work with.

ii. Tell me about the community you serve.

d. What is it like when you are at work but outside of the station?

\section{Communication and Technology}

2. List the different kinds of technology (devices, equipment) you use to do your job.

a. How would you describe the technology/equipment you currently use?

b. Are there apps that you use to do your job?

c. Have there been times when technology has gotten in the way?

3. How (if at all) have things changed in terms of communication since you became a first responder?

a. Do these changes make communication better or worse for you?

4. In a typical day on your job, what kinds of information do you need?

a. Are there other kinds of information you need for situations that aren't so typical-and if so, what is it?

5. If you think about the incidents you've responded to over the last few weeks or months, is there information that could have helped you understand the scene before you got there? Tell me about it.

a. What kind of information would be the most helpful, either for typical or for more complicated calls?

b. How would you want to get that information?

6. What, if anything, do you think causes communication problems in your work?

a. What, if anything, could help with these problems?

7. Let's talk out of the box for a minute, describe your technology wish list: pie in the sky here, if technology could do whatever you wanted it to, what would you want?

a. Are there new or different apps you can think of that could be useful?

8. Is there anything else you'd like to share about your job that you think is important for us to know?

9. Do you have any questions for me/us? 


\section{Appendix C: Demographic Questionnaire}

Your area(s): $\square$ Fire $\quad \square$ EMS $\quad \square$ Law Enforcement $\square$ Dispatch

$\square$ Other Public Safety:

Total years of service:

Location: $\quad \square$ Urban $\quad \square$ Suburban $\quad \square$ Rural $\quad \square$ Tribal $\quad \square$ Other:

City, State:

Gender: $\quad \square$ Female $\quad \square$ Male $\quad \square$ Prefer not to answer

Age: $\quad \square$ 18-25 $\square$ 26-35 $\square$ 36-45 $\square$ 46-55 $\square$ 56-65 $\quad \square$ Over 65

\section{Experience with different kinds of technology:}

(including desktop or laptop computers, tablets, smartphones, and the Internet).

I have limited experience using technology and I don't know much about how technology works.

I have some knowledge about how technology works, but often need to ask for help to perform more advanced activities - such as to configure the privacy settings on my cell phone.

I can do most things that I want to do with technology and only need help occasionally.

I can do all things that I want to do with technology without help from others.

In general, when do you adopt new technologies?

I try the latest technologies as soon as they come out.

I follow technology trends.

I let others work out the kinks first.

$\square$ I wait until my old technology dies.

$\square$ I only adopt new technologies when it's required. 